\title{
The Charge State of Pt in Binary Compounds and Synthetic Minerals Determined by X-ray Absorption Spectroscopy and Quantum Chemical Calculations
}

\author{
Polina V. Evstigneeva ${ }^{1}$, Alexander L. Trigub ${ }^{2}$, Dmitriy A. Chareev ${ }^{3,4,5}$, Max S. Nickolsky ${ }^{1}$ (D) \\ and Boris R. Tagirov ${ }^{1, *}$ \\ 1 Institute of Geology of Ore Deposits, Petrography, Mineralogy and Geochemistry (IGEM RAS), \\ 35 Staromonetnyi per., 119017 Moscow, Russia; evstpolinav@gmail.com (P.V.E.); \\ mnickolsky@gmail.com (M.S.N.) \\ 2 National Research Centre 'Kurchatov Institute', 1 Akademika Kurchatova Square, 123182 Moscow, Russia; \\ alexander.trigub@gmail.com \\ 3 Institute of Experimental Mineralogy (IEM RAS), 142432 Chernogolovka, Moscow Region, Russia; \\ charlic@mail.ru \\ 4 Institute of Physics and Technology, Ural Federal University, 19 Mira St., 620002 Ekaterinburg, Russia \\ 5 Institute of Geology and Petroleum Technologies, Kazan Federal University, 18 Kremlyovskaya St., \\ 420008 Kazan, Russia \\ * Correspondence: boris1t@yandex.ru
}

check for updates

Citation: Evstigneeva, P.V.; Trigub, A.L.; Chareev, D.A.; Nickolsky, M.S.; Tagirov, B.R. The Charge State of Pt in Binary Compounds and Synthetic Minerals Determined by X-ray Absorption Spectroscopy and Quantum Chemical Calculations. Minerals 2021, 11, 79. https:// doi.org/10.3390/min11010079

Received: 30 October 2020 Accepted: 12 January 2021 Published: 15 January 2021

Publisher's Note: MDPI stays neutral with regard to jurisdictional clai$\mathrm{ms}$ in published maps and institutional affiliations.

Copyright: (C) 2021 by the authors. Licensee MDPI, Basel, Switzerland. This article is an open access article distributed under the terms and conditions of the Creative Commons Attribution (CC BY) license (https:// creativecommons.org/licenses/by/ $4.0 /)$.
Abstract: The binary synthetic compounds of Pt with chalcogens (O, S, Se, Te), pnictogens (As, Sb, $\mathrm{Bi}$ ), and intermetallic compounds with $\mathrm{Ga}$, In, and $\mathrm{Sn}$ of various stoichiometry were studied via X-ray absorption spectroscopy (XAS). The partial atomic charges of Pt in the compounds were computed using quantum chemical density functional theory (DFT) based methods: the Bader (QTAIM) method, and the density-derived electrostatic and chemical (DDEC6) approach. Strong positive correlations were established between the calculated partial atomic charges of $\mathrm{Pt}$ and the electronegativity $(\chi)$ of ligands. The partial charge of $\mathrm{Pt}$ in $\mathrm{PtL}_{2}$ compounds increases much sharply when the ligand electronegativity increases than the Pt partial charge in PtL compounds. The effect of the ligand-to-Pt atomic ratio on the calculated Pt partial charge depended on ligand electronegativity. The DDEC6 charge of $\mathrm{Pt}$ increases sharply with the growth of the number of ligands in $\mathrm{PtS}_{\mathrm{n}}(\mathrm{n}=1,2$; electronegativity $\chi(\mathrm{S})>>\chi(\mathrm{Pt}))$, weakly depends on the phase composition in $\mathrm{PtTe}_{\mathrm{n}}(\mathrm{n}=1,2 ; \chi(\mathrm{Te})$ is slightly lower than $\chi(\mathrm{Pt})$ ), and decreases (becomes more negative) with increase of the ligand-to-Pt ratio in intermetallic compounds with electron donors $(\chi(\mathrm{L})<\chi(\mathrm{Pt}), \mathrm{L}=\mathrm{Ga}, \mathrm{In}, \mathrm{Sn})$. According to XANES spectroscopy, the number of $5 d$ ( $L_{2,3}$ absorption edges) and $6 p$ ( $L_{1}$-edge) electrons at the $\mathrm{Pt}$ site decreased when ligand electronegativity increased in chalcogenides and pnictides groups. An increase of the ligand-to-Pt ratio resulted in the increase of the $\mathrm{Pt} L_{3}$-edge white line intensity and area in all studied compounds. In the case of chalcogenides and pnictides, this behavior was consistent with the electronegativity rule as it indicated a loss of $\mathrm{Pt} 5 d$ electrons caused by the increase of the number of ligands, i.e., acceptors of electrons. However, in the case of ligands-electron donors (Te, Sn, Ga, In) this observation is in apparent contradiction with the electronegativity arguments as it indicates the increase of the number of Pt $5 d$-shell vacancies (holes) with the increase of the number of the ligands, for which the opposite trend is expected. This behavior can be explained in the framework of the charge compensation model. The loss of the $\mathrm{Pt} d$-electrons in compounds with low ligand electronegativity $(\chi(\mathrm{Pt})>\chi(\mathrm{L}))$ was overcompensated by the gain of the hybridized $s-p$ electron density, which was confirmed by $\mathrm{Pt} L_{1}$ - edge spectra analysis. As a result, the total electron density at the $\mathrm{Pt}$ site followed the electronegativity rule, i.e., it increased with the growth of the number of the ligands-electron donors. The empirical correlations between the Pt partial atomic charges and parameters of XANES spectral features were used to identify the state of $\mathrm{Pt}$ in pyrite, and can be applied to determine the state of $\mathrm{Pt}$ in other ore minerals.

Keywords: X-ray absorption spectroscopy; DFT calculations; partial atomic charges; Bader charges; DDEC charges; platinum; synthetic minerals; pyrite 


\section{Introduction}

Binary Pt compounds with chalcogens ( $\mathrm{S}, \mathrm{Se}, \mathrm{Te}$ ), pnictogens (As, Sb, Bi), and intermetallic compounds belong to the main ore minerals in platinum group element (PGE) deposits, including the world-class deposits of the Norilsk group (Russian Federation), the Bushveld Complex (South Africa), and the Stillwater Complex (USA) (Distler et al. [1]; Cabri [2] and the references cited). The "formal" oxidation states of Pt in these compounds are $0,+2$, and +4 . These oxidation states, however, are in contravention of the concept of electronegativity and ignore chemical bond type. For example, the "formal" oxidation states of $\mathrm{Pt}$ in sperrylite $\mathrm{PtTe}_{2}$ and cooperite $\mathrm{PtS}$ are +4 and +2 , respectively. At the same time, the Pauling electronegativity of $\mathrm{S}$ exceeds $\mathrm{Te}(\chi(\mathrm{S})=2.58$ vs. $\chi(\mathrm{Te})=2.10$ (Cotton and Wilkinson [3]), which implies that the true positive charge located on $\mathrm{Pt}$ in $\mathrm{Pt}^{2+} \mathrm{S}$ can exceed the $\mathrm{Pt}$ charge in $\mathrm{Pt}^{4+} \mathrm{Te}_{2}$. Other important carriers of PGEs in natural ores are sulfides of $\mathrm{Fe}$, $\mathrm{Ni}$, and $\mathrm{Cu}$ (pyrrhotite $\mathrm{Fe}_{1-\mathrm{x}} \mathrm{S}$, pyrite $\mathrm{FeS}_{2}$, pentlandite $(\mathrm{Fe}, \mathrm{Ni})_{9} \mathrm{~S}_{8}$, chalcopyrite $\mathrm{CuFeS}_{2}$ ), which contain PGEs in the "invisible" form. The charge state of Pt in binary compounds is an important factor that controls the solubility of $\mathrm{PtL}_{n}$ (where $\mathrm{L}$ stands for a ligand) in base metal sulfides (pyrrhotite, pyrite, pentlandite), miscibility limits, and charge compensation schemes. Apart from natural minerals, knowledge of the electronic structure of PGE-based materials has important industrial applications. The electronic structure of catalysts and nanoparticles, as well as the chemical composition that includes PGEs, specifies catalytic activity and gives rise to the development of new functional materials (cf. Nishimura et al. [4]).

X-ray absorption spectroscopy (XAS) is widely used to study the short-range ordering in materials and the charge state of atoms. The information contained in the near-edge region of the XAS spectrum (XANES (X-ray absorption near edge structure)) reflects the density of the electron empty states of the absorbing atom. In particular, parameters of the spectral features at $L_{2,3}$ absorption edges of $\mathrm{Pt}$, which correspond to the $2 p \rightarrow 5 d$ photoelectron transitions, were attributed to the number of vacancies (unoccupied electronic states) in the $5 d$ valence shell (Mott [5]; Lytle et al. [6]; Mansour et al. [7]; and references cited). The intensity and area of the white line (the first intense peak of the spectrum just above the absorption edge) were used to determine, on a quantitative level, the density of $d$-states in the compounds of Pt and Au (e.g., Mansour et al. [7]; Kuhn and Sham [8]; Bzowski et al. [9]). Currently, a number of studies have been devoted to investigating the charge state of atoms by combination XAS and quantum chemical calculations. The calculated charges differ from the "formal" oxidation states, which are attributed to atoms and assume an ionic type of binding. The studies differ both in the studied objects nature (solids, liquids) and the methods used to calculate the partial (net) atomic charges. Among the methods of quantum chemical calculations that are widely used to study the partial charges are QTAIM-Quantum Theory of Atoms in Molecules (Bader method) (Bader et al. [10], Bader and Matta [11]), NBO-Natural bond orbital population analysis (Reed et al. [12]), ChelpG-Charges from Electrostatic Potentials using a Grid-based method, and recently developed DDEC - Density Derived Electrostatic and Chemical method (Manz and Sholl $[13,14])$. For example, Li et al. [15] computed the partial charge of Mo in its compounds of different "formal" oxidation states $\left(\mathrm{MoS}_{2}, \mathrm{Mo}_{2} \mathrm{C}, \mathrm{MoO}_{2}, \mathrm{RbMoO}_{4}\right.$, $\mathrm{MoO}_{3}$ ) using QTAIM and DDEC methods. The calculation results were correlated with the position of the absorption edge of Mo K-edge X-ray absorption spectra. The authors found that DDEC charges correlated better with XANES energies than Bader charges. Kaur et al. [16] performed a similar investigation for Dy compounds. Fogarty et al. [17,18] calculated the partial charges of $\mathrm{N}$ and $\mathrm{S}$ in various ionic liquids using the QTAIM, ChelpG, and NBO methods. The authors compared the calculation results with the experimental $\mathrm{X}$-ray photoelectron spectra (XPS) and XANES spectra. They determined that ChelpG is the most suitable method for determining the atomic charges of $\mathrm{N}$ and $\mathrm{S}$ in ionic liquids.

The present study is comprised of two parts: theoretical calculation of partial atomic charges of Pt in binary compounds (1) and an experimental investigation of valence electron density distribution in binary Pt compounds using XAS (2). To determine the effect of the 
chemical composition on the charge state of $\mathrm{Pt}$, we synthesized the phases and registered XANES spectra at Pt $L_{1,2,3}$ - edges with subsequent determination of the main spectral characteristics (the positions of the absorption edge and white line, white line intensity and area). These data were correlated with partial atomic charges calculated using QTAIM and DDEC. The strong correlations between the partial charges calculated with the DDEC approach, ligand electronegativities, and XANES spectra parameters were observed in each compound group. The correlation for chalcogenides was validated by determining the Pt partial charge in synthetic Pt-bearing pyrite. The obtained data provided a basis for evaluating the state of $\mathrm{Pt}$ in inorganic compounds and can be extended to higher number of ligands and to multicomponent natural minerals.

\section{Materials and Methods}

\subsection{Synthesis of Platinum Phases}

Pt compounds were synthesized using a dry synthesis method according to Kullerud [19]. The starting materials were elements with a purity of $>99 \mathrm{wt} . \%$. The mass of the initial charge was $\sim 400 \mathrm{mg}$. The stoichiometric quantities of elements were weighed and placed into the silica glass ampoules ( $8 \mathrm{~mm}$ diameter, $\sim 80 \mathrm{~mm}$ length), which were then evacuated down to a $10^{-4}$ bar pressure and sealed. Several experiments were performed with slight excess of the second component to ensure the absence of metallic $\mathrm{Pt}$ in the synthesis products. The excess of the component crystallized at the cold end of the ampoule during quenching. The ampoules with the charges were placed in the horizontal tube furnace and heated to the synthesis temperature. The temperature depended on the thermal stability of the phases and was selected individually in each case based on the binary phase diagrams (Lyakishev [20-22]). The parameters for the synthesis experiments are given in Table 1. The temperature inside the furnace was measured with a K-type thermocouple (accuracy $\pm 1{ }^{\circ} \mathrm{C}$ ). One time, during the experiment, the ampoules were removed from the furnace, opened, the powders were grounded, then sealed again inside the silica glass ampoules, and rapidly heated to the synthesis temperature. After the experiment, the ampoules were quenched either on air or in cold water.

Table 1. Temperature and duration of synthesis of 18 Pt-bearing phases. The two temperatures for one substance correspond to the two-stage synthesis experiments.

\begin{tabular}{|c|c|c|c|c|c|}
\hline Phase & Temperature, ${ }^{\circ} \mathrm{C}$ & Synthesis Time, Days & Phase & Temperature, ${ }^{\circ} \mathrm{C}$ & Synthesis Time, Days \\
\hline $\mathrm{PtS}_{2}$ & 850 & 90 & $\mathrm{Ga}_{3} \mathrm{Pt}_{5}$ & $\begin{array}{l}800 \\
600\end{array}$ & $\begin{array}{c}2 \\
45\end{array}$ \\
\hline $\mathrm{PtSe}_{2}$ & $\begin{array}{l}550 \\
400\end{array}$ & $\begin{array}{c}2 \\
45\end{array}$ & $\mathrm{GaPt}$ & 600 & 45 \\
\hline $\mathrm{PtTe}_{2}$ & $\begin{array}{l}800 \\
600\end{array}$ & $\begin{array}{c}2 \\
45\end{array}$ & $\mathrm{Ga}_{3} \mathrm{Pt}_{2}$ & 800 & 45 \\
\hline $\mathrm{PtAs}_{2}$ & 700 & 45 & $\mathrm{Ga}_{7} \mathrm{Pt}_{3}$ & 600 & 45 \\
\hline $\mathrm{PtSb}_{2}$ & 600 & 45 & PtIn & $\begin{array}{l}800 \\
600\end{array}$ & $\begin{array}{c}2 \\
45\end{array}$ \\
\hline $\mathrm{PtBi}_{2}$ & 400 & 45 & $\mathrm{Pt}_{2} \mathrm{In}_{3}$ & $\begin{array}{l}800 \\
600\end{array}$ & $\begin{array}{c}2 \\
45\end{array}$ \\
\hline $\mathrm{PtSn}$ & 600 & 45 & $\mathrm{Pt}_{3} \mathrm{In}_{7}$ & 600 & 45 \\
\hline $\mathrm{Pt}_{2} \mathrm{Sn}_{3}$ & $\begin{array}{l}800 \\
600\end{array}$ & $\begin{array}{c}2 \\
45\end{array}$ & PtTe & $\begin{array}{l}800 \\
600\end{array}$ & $\begin{array}{c}2 \\
45\end{array}$ \\
\hline $\mathrm{PtSn}_{2}$ & $\begin{array}{l}700 \\
600\end{array}$ & $\begin{array}{c}2 \\
45\end{array}$ & $\mathrm{PtS}$ & 850 & 180 \\
\hline
\end{tabular}




\subsection{Analytical Methods}

The chemical composition and homogeneity of synthesized phases were studied with a digital scanning electron microscope TESCAN Vega II XMU with the energy-dispersive micro-analysis system INCA Energy 450/XT (20 kV) on polished sections. Pure elements were used as standards for $\mathrm{Pt}, \mathrm{Se}, \mathrm{Te}, \mathrm{Sb}, \mathrm{Bi}$, and $\mathrm{Sn}$, as well as $\mathrm{GaP}$, InAs, $\mathrm{FeS}_{2}$ for $\mathrm{Ga}$, In, As, and $S$, respectively. Each sample was studied with powder X-ray diffractometry. The XRD data were collected on a Rigaku D/Max 2200 X-ray diffractometer $(\mathrm{CuK \alpha}, 40 \mathrm{kV}, 20 \mathrm{~mA}$, $0.02^{\circ}$ step) in the angular range from 5 to $90^{\circ} 2 \theta$. Crystalline phases were identified with an aid of PDF and ICSD databases. All studied samples corresponded to pure homogeneous crystalline phases of definite composition.

\subsection{X-ray Absorption Spectroscopy (XAS)}

The spectra of synthetic platinum phases were recorded using the equipment of Kurchatov Synchrotron Radiation Source (National Research Center Kurchatov Institute, Moscow, Russia). The synchrotron radiation source was a storage ring with an electron beam energy of $2.5 \mathrm{GeV}$ and a current in the range of 50-120 mA. The experiments were performed at the "Material structure" beamline (Chernyshov et al. [23]). Channel-cut $\mathrm{Si}(111)$ single crystal monochromator was used for monochromatization of the X-ray beam with an energy resolution $\Delta \mathrm{E} / \mathrm{E}=2 \times 10^{-4}$. All the samples were ground finely, spread over Kapton tape, and folded into several layers. The Pt foil spectrum was measured simultaneously with the sample as a reference for energy calibration. The XAS spectra of platinum compounds and the reference, $\mathrm{Pt}$ foil, were registered in transmission mode at the $\mathrm{Pt} L_{1^{-}}(13,880 \mathrm{eV}), L_{2}-(13,273 \mathrm{eV})$, and $L_{3}(11,564 \mathrm{eV})$-edges. The $\mathrm{X}$-ray intensity was measured using three tandem ionization chambers filled with a mixture of $\mathrm{N}_{2}$ and Ar. The studied sample was placed between the 1st and 2nd chambers and the reference between the 2nd and 3rd chambers. The energy step to $30 \mathrm{eV}$ before the edge and up to $80 \mathrm{eV}$ above the edge was $0.6 \mathrm{eV}$ for $\mathrm{Pt} L_{3}$-edge and $0.8 \mathrm{eV}$ for $\mathrm{Pt} L_{1}$ - and $L_{2}$-edges. Then, the energy step gradually increased from 1.0 to $3.5 \mathrm{eV}$ for all edges. The integration time in every energy point was set to $1 \mathrm{~s}$. In each case, up to three spectra were collected for their further averaging. Background subtraction and spectra normalization were carried out using the Athena program of the IFEFFIT software package (Ravel et al. [24]). A pre-edge background was subtracted from the entire spectrum. The obtained spectra were normalized using fitted EXAFS data beyond the near-edge structure. The energy range where the spectra were collected, together with the energy ranges applied for the background correction and normalization of the spectra, are given in Supplementary Materials A1.

In each case, the following XANES spectrum parameters were determined: (1) position of the absorption edge, $\mathrm{E}_{0}$; (2) position of the white line (first intense peak of the spectrum),

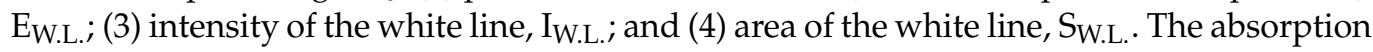
edge was determined as the first maximum of the first derivative of the signal; the position of the white line corresponded to the first maximum of the spectra. The white line intensity corresponded to the difference in the X-ray absorption coefficient between the background line and the maximum of the white line. The area of the white line was determined by deconvoluting the white line feature into an arctangent and Lorentzian components using the Athena program. In this method, the white line area was equal to the area of Lorentzian peak. To obtain stable and meaningful results, several restrictions were applied during the experimental spectra deconvolution procedure. The restrictions included (i) position of the centroid of the Lorentz curve was fixed at the maximum of the white line; (ii) amplitude of the arctangent curve was fixed at the minimum of the fitted XANES spectrum; (iii) width of the arctangent and Lorentz curves should be more than (or about) $2 \mathrm{eV}$ since the natural broadening of a Pt $L_{3}$-edge XANES spectrum is nearly $2-3 \mathrm{eV}$.

The second method to calculate the area under the white line was to integrate the approximating functions (arctangent and Lorentzian) using the MATHCAD 14 program. In this method, deconvolution results for the experimental spectra were obtained using the Athena program (parameters of the arctangent and Lorentzian functions) and were 
loaded into the MATHCAD. The areas were determined via means of integration of the approximating functions, and the sum of the integrals was assigned to the total white line area. The second method was applied only to the Pt dichalcogenides to compare the white line areas obtained in our experiments with the literature data.

\subsection{Quantum Chemical Calculations}

The quantum chemical density functional theory (DFT) calculations were performed using the QuANTUM ESPRESSO code (Giannozzi et al. [25]). The Projector-augmented wave (PAW) method was used to describe electron-ion-core interactions (Blöhl [26], Kresse and Joubert [27]). The Perdew-Burke-Ernzerhof (PBE) exchange-correlation function (Perdew et al. [28]) was used for the electronic structure calculations within the framework of the self-consistent field (SCF) numerical algorithm. We used the PAW pseudopotentials from the QUANTUM ESPRESSO pseudopotential database: http:/ /www.quantumespresso.org/pseudopotentials. The pseudopotential type and electronic configurations of elements adopted in DFT calculations are provided in Supplementary Materials A2. A plane-wave kinetic energy cutoff and a charge density cutoff were $100 \mathrm{Ry}$ and $1500 \mathrm{Ry}$, respectively. An $8 \times 8 \times 8$ Monkhorst-Pack $k$-points grid was applied to all model structures. The SCF calculations were completed with tolerance better than $10^{-9}$ Ry. In the case of layered structures rVV10, a nonlocal correlation functional (Vydrov and Van Voorhis [29]) was added to account for the van der Waals interactions. The crystallographic data (Supplementary Materials A3, Table A5) were adopted from the ICSD and PDF databases. Based on the DFT calculation results, the values of partial atomic charges were determined in the QTAIM (Bader method) framework using the CRITIC2 software (Otero-de-la-Roza et al. [30,31]), and the DDEC6 method using the Chargemol program [32]. In the QTAIM approach, the surfaces with zero flux of the electron density gradient field determine the atomic basins. The electron density in each basin is assigned to an atom. An alternative method, DDEC6, reproduces the electrostatic potential surrounding the nucleus. Unlike the QTAIM method, in the DDEC6 method, the electron density associated with atoms that can overlap. The assigned charges were calculated to best describe the electrostatic potential. In our study, we used DDEC6 as it is the best-developed version of this method (Manz and Limas [33], Limas and Manz [34]) that works well in an extremely broad range of materials.

For several Pt-bearing phases $\left(\mathrm{PtS}_{2}, \mathrm{PtSn}, \mathrm{Pt}_{2} \mathrm{In}_{3}, \mathrm{PtSb}_{2}, \mathrm{Pt}_{2} \mathrm{Ga}_{3}\right)$, pure and $\mathrm{Pt}$-bearing pyrite in atomic positions and cell parameters were optimized. The calculations were performed using the BFGS algorithm in the unit cell $(8 \times 8 \times 8 k$-points, binary compounds $)$ or at a gamma point in $2 \times 2 \times 2$ supercell (pure and Pt-bearing pyrite), with a convergence threshold of $10^{-3} \mathrm{Ry} / \mathrm{au}$ for forces, and $10^{-4} \mathrm{Ry}$ for energy. Determination of the partial atomic charges was performed as described above.

\section{Results}

The correlations between the Pt partial atomic charge and the parameters of XANES spectral features were determined for 21 Pt-bearing phases, which we divided into 6 groups: (1) chalcogenides PtChal $2: \mathrm{PtO}_{2}, \mathrm{PtS}_{2}, \mathrm{PtSe}_{2}, \mathrm{PtTe}_{2} ;$ (2) pnictides PtPn 2 : $\mathrm{PtAs}_{2}, \mathrm{PtSb}_{2}$, and $\mathrm{PtBi}_{2} ;$ (3) intermetallic compounds $\mathrm{Pt}_{x} \mathrm{Sn}_{y}$ : $\mathrm{PtSn}, \mathrm{Pt}_{2} \mathrm{Sn}_{3}$, and $\mathrm{PtSn}_{2} ;$ (4) intermetallic compounds $\mathrm{Pt}_{x} \mathrm{Ga}_{y}$ : $\mathrm{PtGa}, \mathrm{Pt}_{2} \mathrm{Ga}_{3}, \mathrm{Pt}_{5} \mathrm{Ga}_{3}$, and $\mathrm{Pt}_{3} \mathrm{Ga}_{7}$; (5) intermetallic compounds $\mathrm{Pt}_{x} \mathrm{In}_{y}$ : $\mathrm{PtIn}, \mathrm{Pt}_{2} \mathrm{In}_{3}$, and $\mathrm{Pt}_{3} \mathrm{In}_{7}$; and (6) Other: $\mathrm{PtTe}, \mathrm{PtS}, \mathrm{K}_{2} \mathrm{PtCl}_{4}$, and Pt. In the PtChal 2 and $\mathrm{PtPn}_{2}$ groups, the ligand type was the distinctive feature; in the $P t_{x} S n_{y}, P t_{x} G a_{y}$, and $P t_{x} I n_{y}$ groups, the ligand-to-Pt ratio (i.e., stoichiometry) was the distinctive feature.

\subsection{Partial Atomic Charges}

Comparison of the Pt partial atomic charges computed before and after crystal structure relaxation (optimization of atomic positions and cell parameters) shows that the relaxation of the crystal structure leads to a minor difference in partial charges. For example, the calculated DDEC6 charges of Pt with and without geometry optimization were +0.48 and +0.47 in $\mathrm{PtS}_{2},-0.26$ and -0.26 in $\mathrm{PtSn},-0.47$ and -0.46 in $\mathrm{Pt}_{2} \mathrm{In}_{3},-0.22$ and 
-0.20 in $\mathrm{PtSb}_{2}$, and -0.37 and -0.39 in $\mathrm{Pt}_{2} \mathrm{Ga}_{3}$. In view of the small difference in the calculated values, only partial charges calculated using crystal structures without geometry optimization are discussed in this work. The calculated partial charges are given in Table 2 and shown in Figure 1.

The effect of the ligand Pauling electronegativity $(\chi)$ on the Bader and DDEC6 charges were similar within the selected groups. The partial charge of Pt decreased (becomes more negative) with decrease of the ligand electronegativity within the $P t C h a l_{2}, P t P n_{2}$, and Other groups. The exception was the Bader charge of $\mathrm{PtSb}_{2}$ in $\mathrm{PtPn}_{2}$ group, wherein the Pt charge was expected to decrease in the series of $\mathrm{PtAs}_{2}, \mathrm{PtSb}_{2}$, and $\mathrm{PtBi}_{2}(\chi(\mathrm{As})=2.18>\chi(\mathrm{Sb})=2.05 \approx \chi(\mathrm{Bi})=2.02)$. However, the largest negative Bader charge was assigned to $\mathrm{PtSb}_{2}$. In all other compound groups, the correlations between the DDEC6, QTAIM charges, and ligand Pauling electronegativity were identical. Therefore, the use of both DDEC6 and QTAIM charges was appropriate for the purposes of the present study. The DDEC6 charges were considered in the following sections to explore the correlations between the Pt partial atomic charges and the XANES spectra parameters. Similar correlations for the Bader charges are given in Supplementary Materials A4-A6.

Table 2. Results of DFT calculations of the Pt partial atomic charges (without geometry optimization).

\begin{tabular}{|c|c|c|c|c|c|}
\hline \multirow{2}{*}{ Phase } & \multirow{2}{*}{ Mineral Analogue } & \multirow{2}{*}{ Crystal System } & \multicolumn{2}{|c|}{ Computed Partial Charges of Pt } & \multirow{2}{*}{$\begin{array}{l}\text { Pauling Electronegativity } \\
\text { of Ligand }\end{array}$} \\
\hline & & & Bader & DDEC6 & \\
\hline \multicolumn{6}{|c|}{$\mathrm{PtChal}_{2}$} \\
\hline $\mathrm{PtO}_{2}$ & & trigonal & +1.60 & +1.14 & 3.44 \\
\hline $\mathrm{PtS}_{2}$ & & trigonal & +0.64 & +0.47 & 2.58 \\
\hline $\mathrm{PtSe}_{2}$ & sudovikovite & trigonal & +0.20 & +0.25 & 2.55 \\
\hline $\mathrm{PtTe}_{2}$ & moncheite & trigonal & -0.40 & -0.017 & 2.1 \\
\hline \multicolumn{6}{|c|}{$\mathrm{PtPn}_{2}$} \\
\hline $\mathrm{PtAs}_{2}$ & sperrylite & cubic & -0.30 & +0.069 & 2.18 \\
\hline $\mathrm{PtSb}_{2}$ & geversite & cubic & -1.27 & -0.20 & 2.05 \\
\hline $\mathrm{PtBi}_{2}$ & insizwaite & cubic & -0.78 & -0.26 & 2.02 \\
\hline \multicolumn{6}{|c|}{$\mathrm{Pt}_{\mathrm{x}} \mathrm{Sn}_{\mathrm{y}}$} \\
\hline $\mathrm{PtSn}$ & niggliite & hexagonal & -0.85 & -0.26 & \\
\hline $\mathrm{Pt}_{2} \mathrm{Sn}_{3}$ & & hexagonal & -1.03 & -0.37 & 1.96 \\
\hline $\mathrm{PtSn}_{2}$ & & cubic & -1.17 & -0.47 & \\
\hline \multicolumn{6}{|c|}{$\mathrm{Pt}_{\mathrm{x}} \mathrm{Ga}_{\mathrm{y}}$} \\
\hline & & & $-0.51 \times 8$ & $-0.17 \times 4$ & \multirow{5}{*}{1.81} \\
\hline $\mathrm{Pt}_{5} \mathrm{Ga}_{3}$ & & orthorhombic & $\begin{array}{l}-0.31 \times 8 \\
-0.32 \times 2\end{array}$ & $\begin{array}{l}-0.19 \times 2 \\
-0.09 \times 4\end{array}$ & \\
\hline $\mathrm{PtGa}$ & & cubic & -0.68 & $\begin{array}{c}-0.09 \times 4 \\
-0.28\end{array}$ & \\
\hline $\mathrm{Pt}_{2} \mathrm{Ga}_{3}$ & & trigonal & -0.94 & -0.39 & \\
\hline $\mathrm{Pt}_{3} \mathrm{Ga}_{7}$ & & cubic & -1.09 & -0.46 & \\
\hline \multirow{4}{*}{ PtIn } & & & $\mathrm{Pt}_{\mathrm{x}} \operatorname{In}_{\mathrm{y}}$ & & \multirow{6}{*}{1.78} \\
\hline & & & $-0.68 \times 2$ & $-0.36 \times 6$ & \\
\hline & & monoclinic & $-0.72 \times 4$ & $-0.29 \times 4$ & \\
\hline & & & $-0.71 \times 4$ & $-0.29 \times 1$ & \\
\hline $\mathrm{Pt}_{2} \mathrm{In}_{3}$ & & trigonal & -0.98 & -0.46 & \\
\hline $\mathrm{Pt}_{3} \mathrm{In}_{7}$ & & cubic & -1.09 & -0.49 & \\
\hline \multicolumn{6}{|c|}{ Other } \\
\hline PtTe & & trigonal & -0.33 & -0.08 & 2.1 \\
\hline PtS & cooperite & tetragonal & +0.44 & +0.23 & 2.58 \\
\hline $\mathrm{K}_{2} \mathrm{PtCl}_{4}$ & & tetragonal & +0.66 & +0.30 & 3.16 (for $\mathrm{Cl}$ ) \\
\hline
\end{tabular}




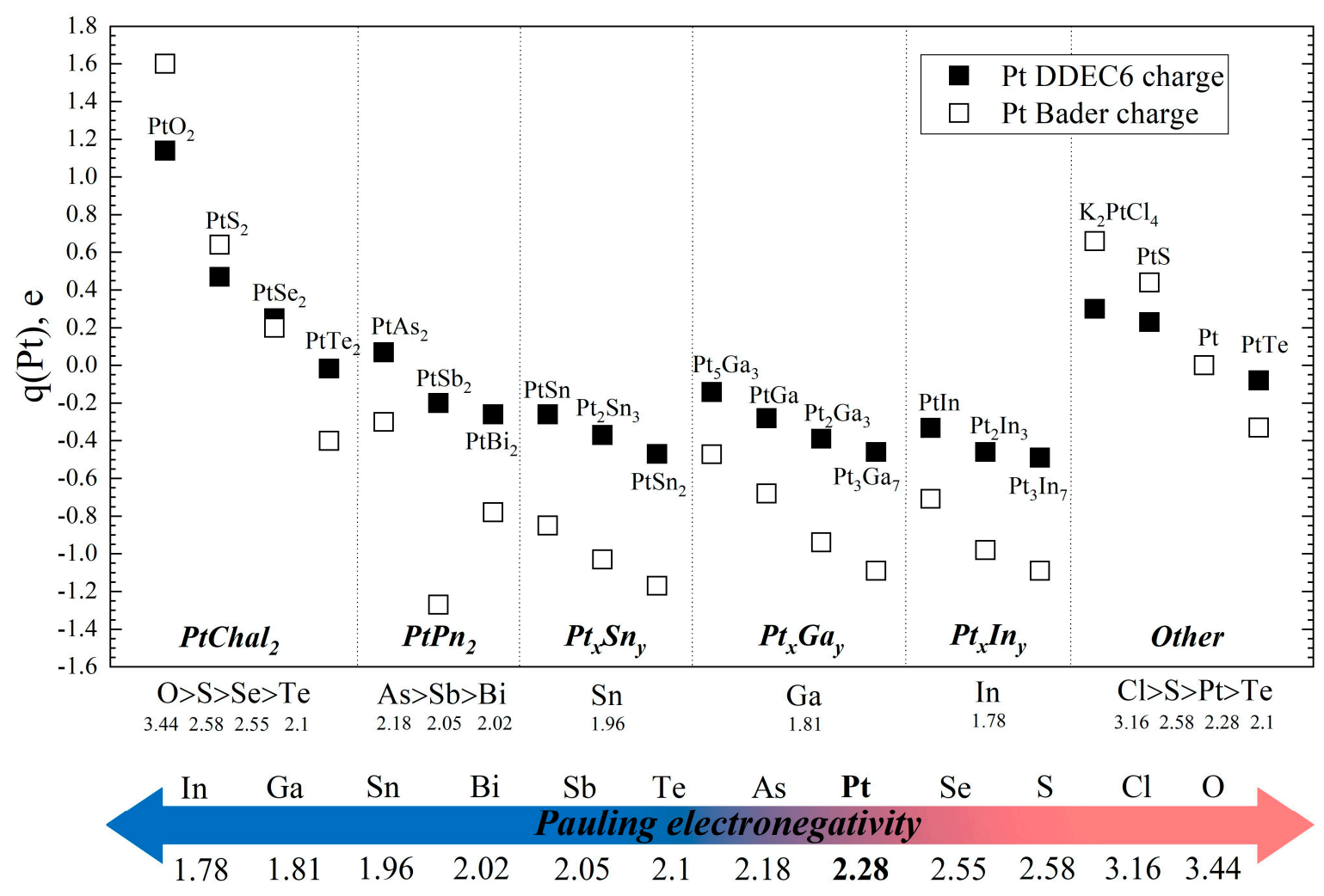

Figure 1. The DDEC6 and Bader QTAIM partial atomic charges for different compound groups. The substances in each group are ordered so that the DDEC6 charge decreases rightward. Symbols show the Pt partial charge calculated using QTAIM and DDEC6 methods. The electronegativity of ligands in each group of compounds is indicated in X axis. The total electronegativity scale for all studied elements is given at the bottom ([3]).

In the intermetallic compounds $P t_{x} S n_{y}, P t_{x} G a_{y}$, and $P t_{x} I n_{y}$ the partial charge of $\mathrm{Pt}$ decreased (Pt gains the valence electron density) when the number of ligands per $\mathrm{Pt}$ atom (ligand-to-Pt atomic ratio) increased. The growth of the negative Pt charge caused by increase in the ligand-to-Pt ratio can be explained by the electron-donor properties of the ligands, which electronegativity lowered. The higher is the number of the ligands-electron donors, the more electron density is shifted towards $\mathrm{Pt}$, thus resulting in the decrease of the Pt partial charge.

\subsection{XANES Spectra Analysis}

The normalized spectra recorded at $\mathrm{Pt} L_{1,2,3}$-edges were collected in the Supplementary Materials B in the format of Athena projects, and shown in Supplementary Materials A4, A5 and A6 (Pt $L_{1^{-}}, L_{2^{-}}$, and $L_{3}$-edges, respectively). Results of the $\mathrm{Pt} L_{1,2,3}$ spectra decomposition (parameters of the arctangent and Lorentzian functions) obtained via the linear combination analysis and the MATHCAD program (for group PtChal ${ }_{2}$ ) are given in Supplementary Materials C.

The parameters of the main spectral features of $\mathrm{Pt} L_{3}$ absorption edge are given in Table 3. It is known from the experimental and theoretical studies that absorption edge generally exhibits a blue shift (towards higher energy) for more oxidized states of an absorbing atom. However, for most studied compounds, the experimental data accuracy $( \pm 0.5 \mathrm{eV})$ is comparable with the effect of the chemical composition on the positions of the absorption edge and the white line maximum. Therefore, we mainly used parameters of the second spectral feature white line intensity and area to correlate the charge state of $\mathrm{Pt}$ with the ligand type and phase (mineral) stoichiometry. The $\mathrm{Pt} L_{1}$ absorption edge was related to $2 s_{1 / 2} \rightarrow 6 p_{1 / 2} / 6 p_{3 / 2}$ dipole-allowed transitions, the $\mathrm{Pt} L_{2}$ absorption to $2 p_{1 / 2} \rightarrow 5 d_{3 / 2}$ transition, and the $\mathrm{Pt} L_{3}$ absorption edge to $2 p_{3 / 2} \rightarrow 5 d_{3 / 2} / 5 d_{5 / 2}$ transitions. Therefore, 
the white line intensity and area were sensitive to the number of empty states (holes) in the corresponding valence orbitals above the Fermi level. Low white line intensity (area) indicates the reduced unoccupied electronic density of states of the valence orbitals of $\mathrm{Pt}$, i.e., the larger number of electrons. Alternatively, an increase of the white line intensity (area) means that the increase of the number of vacancies can be attributed to the loss of the valence electrons localized on the corresponding orbitals: $6 p$ ( $\mathrm{Pt} L_{1}$-edge) or $5 d$ (Pt $L_{2,3}$-edges).

The white line intensity increased markedly from the $\mathrm{Pt} L_{1}$ - to $\mathrm{Pt} L_{3}$-edges because of the dipole selection rules (c.f. [5,7]). The spectra registered at $\mathrm{Pt} L_{1}$-edge had a smooth character and low signal-to-noise ratio, which increased the uncertainty of the calculated parameters of XANES. In some cases $\left(\mathrm{Pt}_{3} \mathrm{In}_{7}, \mathrm{Pt}_{5} \mathrm{Ga}_{7}\right)$, it was impossible to obtain reasonable parameters of the spectral features. The $\mathrm{Pt} L_{2}$ absorption edge spectra were also characterized by smooth peaks, but to a less extent than the $\mathrm{Pt} L_{1}$ spectra. In contrast, $\mathrm{Pt} L_{3}$ spectra had high signal-to-noise ratio and an intensive white line.

The XANES spectra at the $L_{2}$ and $L_{3}$ absorption edges probed the transitions to unoccupied $d$ states, but the unoccupied $\mathrm{Pt} 5 d$ states had mostly $j=5 / 2$ character. Accordingly, the white line intensity at the $\mathrm{Pt} L_{3}$-edge was higher (transitions to $d_{3 / 2}$ and $d_{5 / 2}$ states) than $\mathrm{Pt} L_{2}$-edge (transitions to $d_{3 / 2}$ state, [5]). Therefore, the $\mathrm{Pt} L_{3}$ spectra were the most informative for the investigation of the Pt charge state. Below, we analyzed the $L_{3}$ absorption edge (Figure 2). The $L_{1,2}$ spectra were used as auxiliary ones.

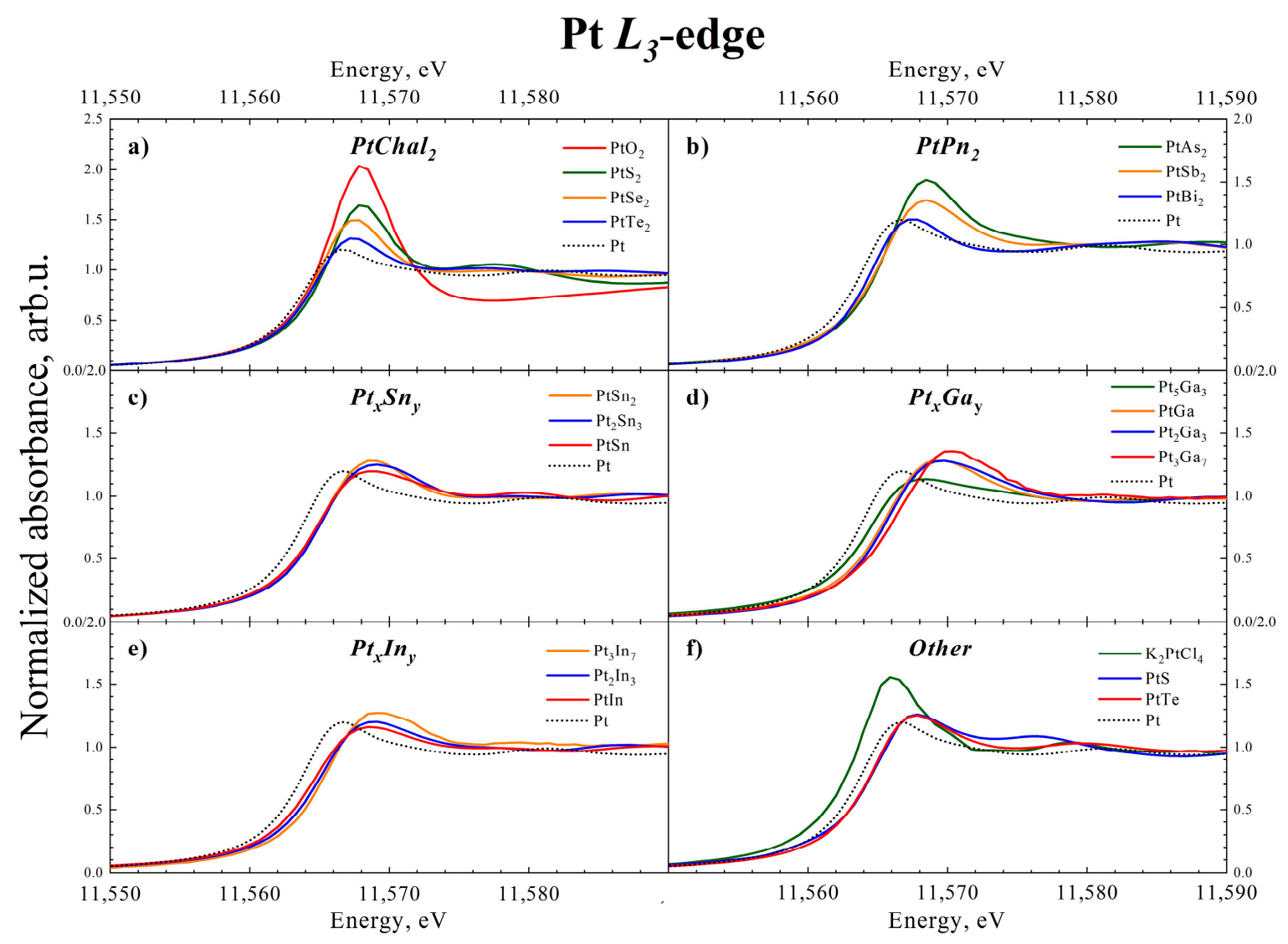

Figure 2. Normalized $P t L_{3}$ XANES spectra. (a) $P t C h a l_{2}$, (b) $P t P n_{2}$, (c) $P t_{x} S n_{y}$, (d) $P t_{x} G a_{y}$, (e) $P t_{x} I n_{y}$, and (f) other groups. 
Table 3. Results of Pt $L_{3}$ XANES spectra deconvolution obtained using Athena program.

\begin{tabular}{|c|c|c|c|c|c|}
\hline \multirow{2}{*}{ Phase } & \multicolumn{4}{|c|}{$L_{3}$} & \multirow{2}{*}{ DDEC6 Charge of $\mathrm{Pt}$, $\mathrm{e}$} \\
\hline & $\mathrm{E}_{0}, \mathrm{eV}$ & $\mathrm{E}_{\mathrm{W} . \mathrm{L} .}, \mathrm{eV}$ & $\mathrm{I}_{\mathrm{W} . \mathrm{L.},}$ arb.u. & $S_{W . L .}, \mathrm{eV}$ & \\
\hline \multicolumn{6}{|c|}{$\mathrm{PtChal}_{2}$} \\
\hline $\mathrm{PtO}_{2}$ & $11,565.6$ & $11,567.8$ & 2.03 & 13.61 & +1.14 \\
\hline $\mathrm{PtS}_{2}$ & $11,565.9$ & $11,567.8$ & 1.64 & 8.24 & +0.47 \\
\hline $\mathrm{PtSe}_{2}$ & $11,565.1$ & $11,567.3$ & 1.50 & 6.03 & +0.25 \\
\hline $\mathrm{PtTe}_{2}$ & $11,564.7$ & $11,567.3$ & 1.30 & 5.45 & -0.017 \\
\hline \multicolumn{6}{|c|}{$\mathrm{PtPn}_{2}$} \\
\hline $\mathrm{PtAs}_{2}$ & $11,565.9$ & $11,568.3$ & 1.51 & 6.97 & +0.069 \\
\hline $\mathrm{PtSb}_{2}$ & $11,565.6$ & $11,568.4$ & 1.35 & 5.97 & -0.20 \\
\hline $\mathrm{PtBi}_{2}$ & $11,564.6$ & $11,567.2$ & 1.20 & 3.92 & -0.26 \\
\hline \multicolumn{6}{|c|}{$\mathrm{Pt}_{\mathrm{x}} \mathrm{Sn}_{\mathrm{y}}$} \\
\hline $\mathrm{PtSn}$ & $11,564.9$ & $11,568.6$ & 1.20 & 5.25 & -0.26 \\
\hline $\mathrm{Pt}_{2} \mathrm{Sn}_{3}$ & $11,565.2$ & $11,569.0$ & 1.25 & 5.46 & -0.37 \\
\hline $\mathrm{PtSn}_{2}$ & $11,565.1$ & $11,568.6$ & 1.28 & 5.25 & -0.47 \\
\hline \multicolumn{6}{|c|}{$\mathrm{Pt}_{\mathrm{x}} \mathrm{Ga}_{\mathrm{y}}$} \\
\hline $\mathrm{Pt}_{5} \mathrm{Ga}_{3}$ & $11,564.6$ & $11,568.1$ & 1.13 & 5.42 & $\begin{array}{l}-0.17 \times 4 \\
-0.19 \times 2 \\
-0.09 \times 4\end{array}$ \\
\hline $\mathrm{PtGa}$ & $11,565.6$ & $11,569.2$ & 1.29 & 6.43 & -0.28 \\
\hline $\mathrm{Pt}_{2} \mathrm{Ga}_{3}$ & $11,565.8$ & $11,569.4$ & 1.28 & 6.76 & -0.39 \\
\hline $\mathrm{Pt}_{3} \mathrm{Ga}_{7}$ & $11,566.9$ & $11,570.6$ & 1.36 & 6.84 & -0.46 \\
\hline \multicolumn{6}{|c|}{$P t_{x} \operatorname{In}_{y}$} \\
\hline PtIn & $11,564.6$ & $11,568.5$ & 1.15 & 4.10 & $\begin{array}{l}-0.36 \times 6 \\
-0.29 \times 4\end{array}$ \\
\hline $\mathrm{Pt}_{2} \mathrm{In}_{3}$ & $11,565.2$ & $11,568.7$ & 1.20 & 4.83 & -0.46 \\
\hline $\mathrm{Pt}_{3} \mathrm{In}_{7}$ & $11,565.6$ & $11,569.3$ & 1.27 & 5.24 & -0.49 \\
\hline \multicolumn{6}{|c|}{ Other } \\
\hline $\mathrm{Pt}$ & $11,563.9$ & $11,566.4$ & 1.20 & 4.82 & 0 \\
\hline PtTe & $11,564.8$ & $11,567.6$ & 1.25 & 5.12 & -0.08 \\
\hline PtS & $11,564.4$ & $11,567.7$ & 1.26 & 6.25 & +0.23 \\
\hline $\mathrm{K}_{2} \mathrm{PtCl}_{4}$ & $11,563.8$ & $11,565.9$ & 1.55 & 6.88 & +0.30 \\
\hline
\end{tabular}

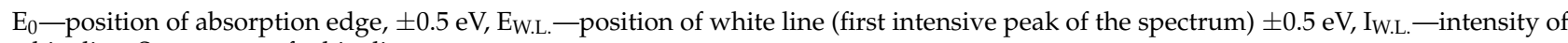
white line, $S_{W . L}$ - area of white line.

\subsection{Correlations between Pt Partial Atomic Charge and XANES Features}

Figures 3 and 4 show the parameters of $\mathrm{Pt} L_{3}$ XANES spectral features (intensity and area) vs. DDEC6 partial atomic charge of Pt. Similar figures for energy position of absorption edge and white line, as well as for Bader partial atomic charges, are given in Supplementary materials A6. In these figures, we plotted the relative XANES characteristics: the energy shift of the absorption edge and white line relative to the values of pure $\mathrm{Pt}$ $\left(\Delta \mathrm{E}_{0}{ }^{\mathrm{Pt}}=\mathrm{E}_{0}{ }^{\mathrm{PtL}}{ }_{\mathrm{n}}-\mathrm{E}_{0}{ }^{\mathrm{Pt}}\right.$ and $\Delta \mathrm{E}_{\text {W.L. }}{ }^{\mathrm{Pt}}=\mathrm{E}_{\text {W.L. }}{ }^{\mathrm{PtL}}{ }_{\mathrm{n}}-\mathrm{E}_{\text {W.L. }}{ }^{\mathrm{Pt}}$, respectively $)$.

In the case of $\mathrm{Pt} L_{3}$-edge, the absorption edge and white line energy were weakly dependent on the Pt partial charge when all compounds were considered together (Supplementary Materials A6, Figures A11, A12). The white line intensity and area were more sensitive to the changes of the charge state of Pt. As shown in Figures 3 and 4, both intensity and white line area increased when the positive Pt partial charge increased. Nonetheless, when all compounds were considered together, the correlation was weak $\left(R^{2}\right.$ Adj. $=0.70$ for the white line intensity, $R^{2}$ dj $=0.73$ for the area). The scattering of the data in the region of negative partial charges was much higher than that of the positive partial charges. The low correlation coefficients can be explained by different trends which are characteristic of different compound groups. Therefore, below, the correlation dependencies were separately analyzed for each group of compounds. 
In the $\mathrm{PtChal}_{2}$ and $\mathrm{PtPn}_{2}$ groups, the Pt partial charge was positively correlated with the Pt $L_{3}$-edge white line intensity (Figure $5 a, b$ ) and area (Figure 6a,b). For example, in the $\mathrm{PtChal}_{2}$ group, the white line intensity $(\mathrm{u}.) / \mathrm{area}(\mathrm{eV})$ increased from $1.30(\mathrm{u}.) / 5.45(\mathrm{eV})$ to 1.64 $(\mathrm{u}) / 8.24(\mathrm{eV})$ with an increase of the DDEC6 Pt charge from $-0.02 \mathrm{e}$ to $+0.47 \mathrm{e}$ between $\mathrm{PtTe}_{2}$ and $\mathrm{PtS}_{2}$. There was a further increase of the $\mathrm{Pt}$ charge to $+1.14 \mathrm{e}$ in $\mathrm{PtO}_{2}$, yielding growth of the white line intensity/area to $2.03(\mathrm{u}.) / 13.61(\mathrm{eV})$. These changes in the white line parameters were accompanied by a small energy increase of the absorption edge and white line caused by the increase of a positive Pt charge due to ligand electronegativity growth. For example, $\mathrm{E}_{0}$ (the absorption edge position) increased from 11,564.7 eV $\left(\mathrm{PtTe}_{2}\right)$ to $11,565.9 \mathrm{eV}\left(\mathrm{PtS}_{2}\right)$, and from $11,564.6 \mathrm{eV}\left(\mathrm{PtBi}_{2}\right)$ to $11,565.9 \mathrm{eV}\left(\mathrm{PtAs}_{2}\right)$. Similar trends were observed in the $\mathrm{Pt} L_{1,2}$ features (Supplementary materials A, Table A6 and Table A7). The positive correlations between the parameters of $\mathrm{Pt} L_{1,2,3}$-edge spectral features and the Pt partial atomic charge were consistent with the effect of the ligand electronegativity on the Pt charge. An increase of the ligand electronegativity caused a density increase of unoccupied states (holes) in the Pt valence orbitals. As a result, the probability of the electronic transitions from the core to the valence orbitals increased and the white line intensity and area grew up. The loss of $5 d$ ( $\mathrm{Pt} L_{2,3}$-edges) and hybridized $6 s p$ ( $\mathrm{Pt} L_{1}$-edge) valence electrons gave rise to the increase of positive charges located on Pt. Accordingly, higher values of the incident energy were needed for the emission of photoelectrons (i.e., the $\mathrm{E}_{0}$ increased).

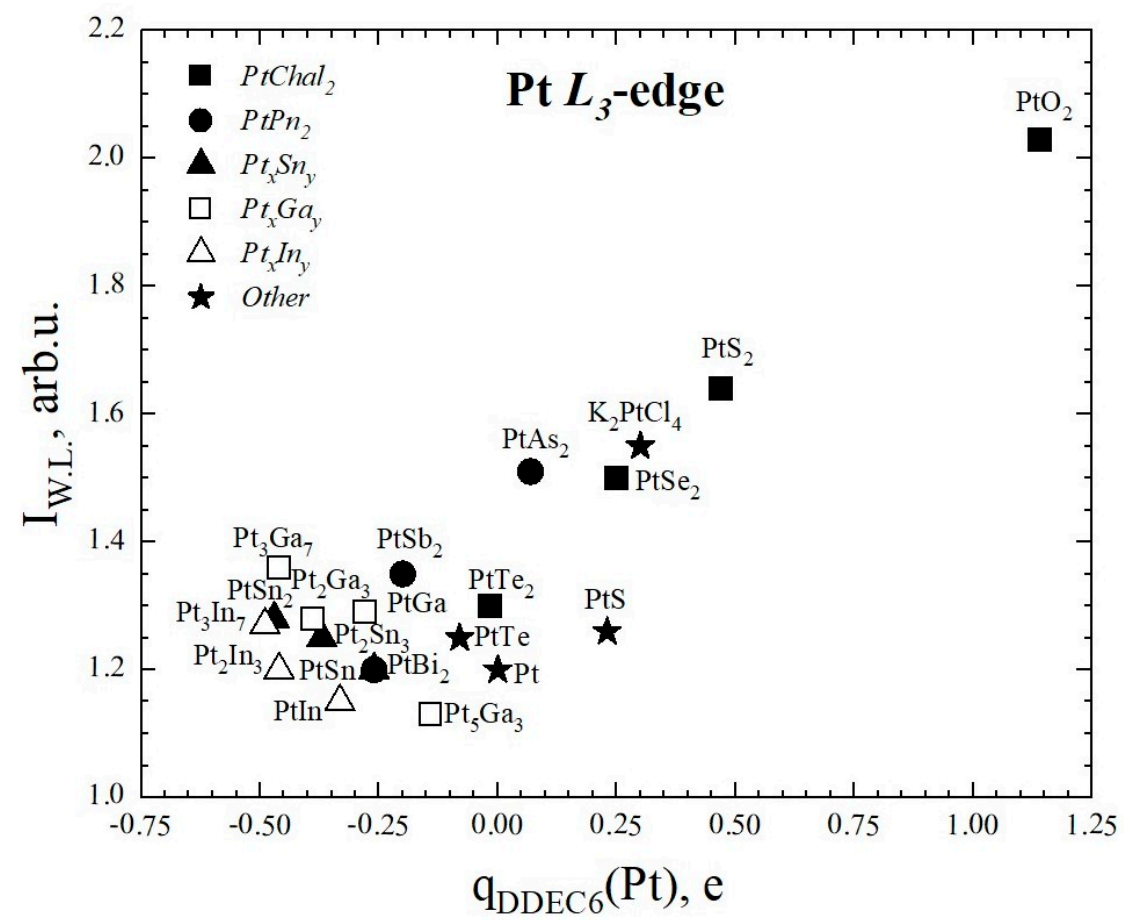

Figure 3. The white line intensity ( $\mathrm{I}_{\text {W.L. }}$ ) of Pt $L_{3}$-edge spectra vs. DDEC6 Pt partial atomic charge. 


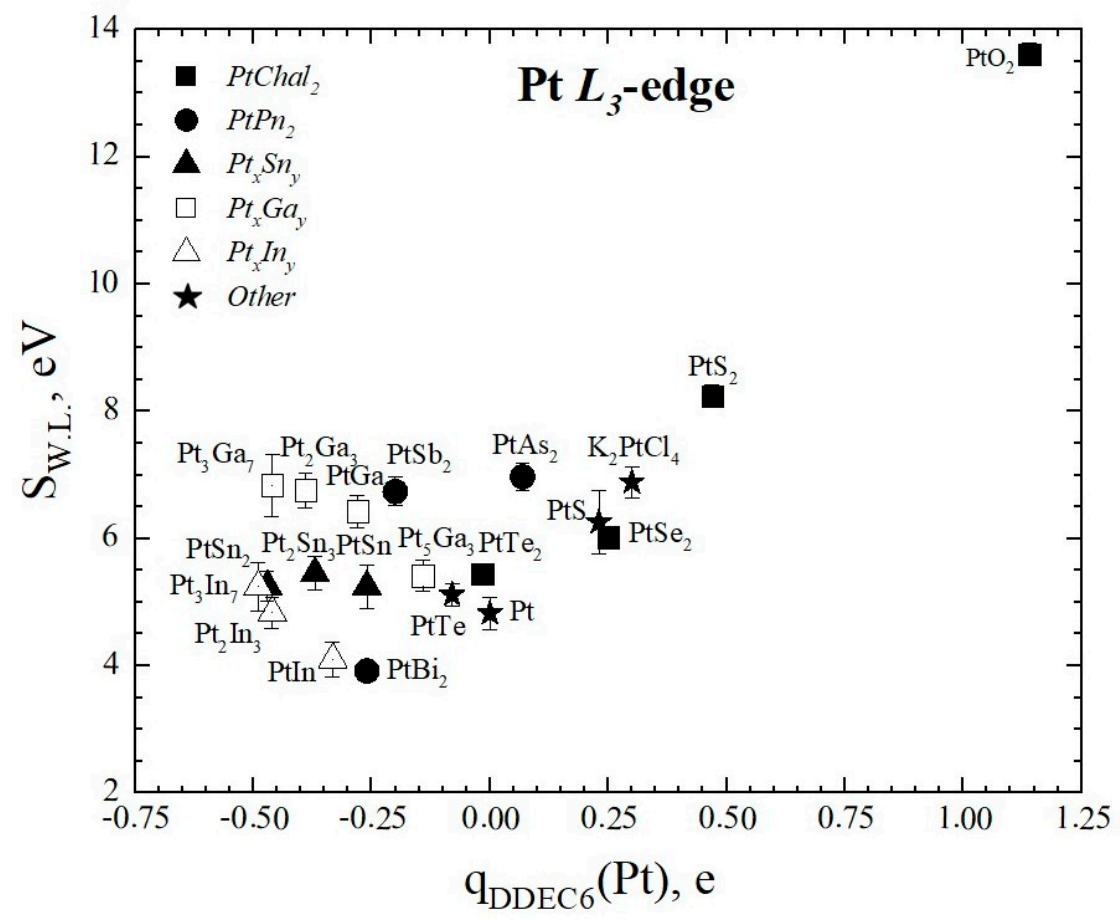

Figure 4. The white line area ( $\mathrm{S}_{\mathrm{W} . \mathrm{L} .}$ ) of $\mathrm{Pt} \mathrm{L}_{3}$-edge spectra vs. DDEC6 Pt partial atomic charge.

In the $P t_{x} S n_{y}, P t_{x} G a_{y}$, and $P t_{x} I n_{y}$ groups, the white line intensity changed less. However, some important peculiarities of the spectral features in the groups of intermetallic compounds were marked out. Figure 7a-c show the "inverse" correlation of the Pt partial charge with the white line intensity at $\mathrm{Pt} L_{3}$-edge compared to $P t C h a l_{2}$ and $P t P n_{2}$. In the $P t_{x} S n_{y}, P t_{x} G a_{y}$, and $P t_{x} I n_{y}$ groups the white line intensity decreased as the partial charge of Pt increased. The same correlation was observed for the white line area in the $P t_{x} G a_{y}$ and $P t_{x} I n_{y}$ groups: an increase of the Pt partial charge resulted in the decrease of the white line area (Figure 8a,b). The positions of the absorption edge and white line of $P t_{x} S n_{y}$ and $P t_{x} I n_{y}$ also exhibited a small but clearly noticeable red shift (towards lower energy) with the increase of the DDEC6 charges (Table 2). The apparent inconsistency between the increase of the partial charge at the $\mathrm{Pt}$ site and a gain of $d$ electrons (decrease of the white line intensity and area) can be explained when the $\mathrm{Pt} L_{1,2,3}$-edges spectra were considered together. The intensity and area of white line at $\mathrm{Pt} L_{2}$-edge followed the "inverse" trend observed for the $\mathrm{Pt} L_{3}$-edge: it decreased when the partially charged $\mathrm{Pt}$ increased (Supplementary Materials A5, Table A7). The white line of the Pt $L_{2,3}$-edges was attributed to a $2 p \rightarrow 5 d$ transition. Accordingly, for the observed "inverse" trend, the increase of the number of ligands-electron donors (leftward in Figures 7 and 8) resulted in the loss of $5 d$ electrons of $\mathrm{Pt}$. At the same time, the white line intensity and area at the $\mathrm{Pt} L_{1}$-edge, which corresponded to a $2 s \rightarrow 6 p$ transition, exhibited a "normal" trend in the $P t_{x} S n_{y}$ and $P t_{x} G a_{y}$ groups (Supplementary Materials A4, Table A6). For example, the white line intensity $(\mathrm{u}) /$ area $(\mathrm{eV})$ decreased from $1.01(\mathrm{u}) / 4.24(\mathrm{eV})$ to $0.94(\mathrm{u}) / 3.16(\mathrm{eV})$ when the ligand-to-Pt ratio increased from $\mathrm{PtSn}$ to $\mathrm{PtSn}_{2}$ (the number of ligands-electron donors per Pt atom increased twofold). A similar drop of the white line area in the $P t_{x} G a_{y}$ group ranged from $3.49 \mathrm{eV}\left(\mathrm{Pt}_{5} \mathrm{Ga}_{3}\right)$ to $1.80 \mathrm{eV}\left(\mathrm{Pt}_{2} \mathrm{Ga}_{3}\right)$. The decrease of the $6 p$ density of unoccupied states (or growth of the electron density at hybridized 6sp Pt orbitals), which was traced when the white line intensity and area decreased, can compensate for the loss of the $d$ electrons and yield the "normal" trend of the total electron density at the Pt site vs. the number of electron-donor ligands. However, we should note that the intensity of the white line at $L_{1}$-edge was small, which made it impossible to quantitatively interpret the charge distribution. 

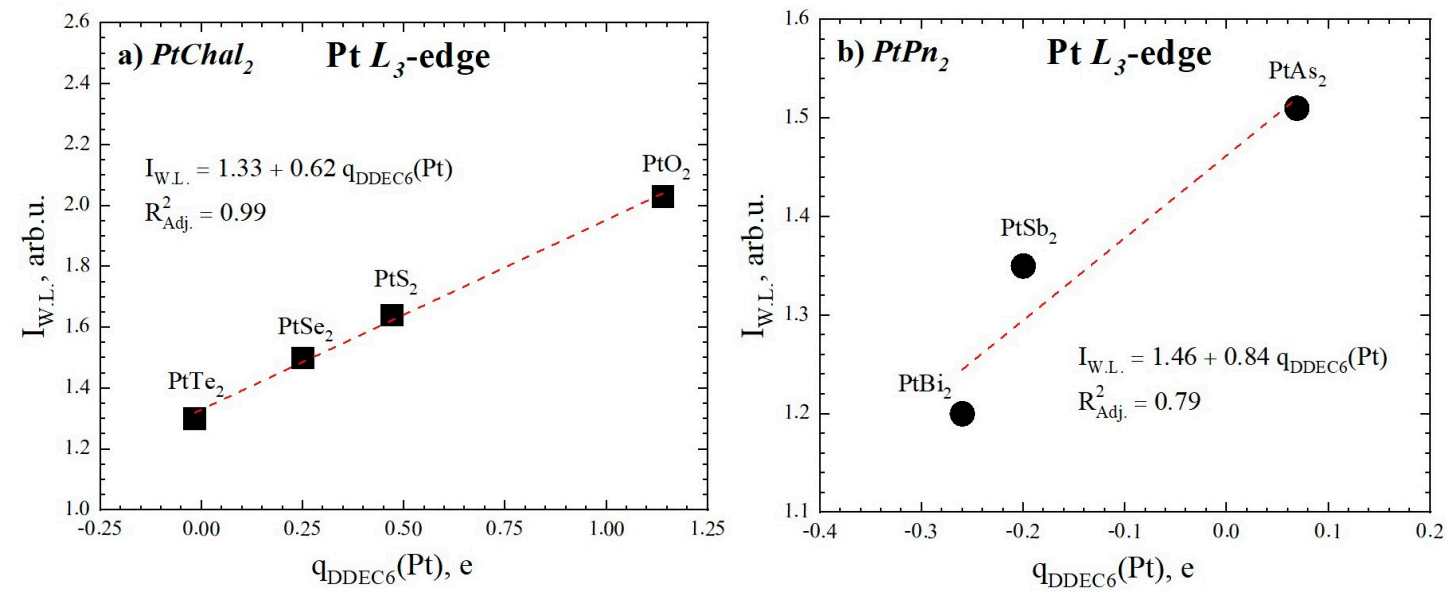

Figure 5. The correlation between intensity of white line ( $\mathrm{I}_{\mathrm{W} . \mathrm{L} .}$ ) of $\mathrm{Pt} L_{3}$ spectra and Pt DDEC6 charge. (a) PtChal 2 and (b) $\mathrm{PtPn}_{2}$ groups.
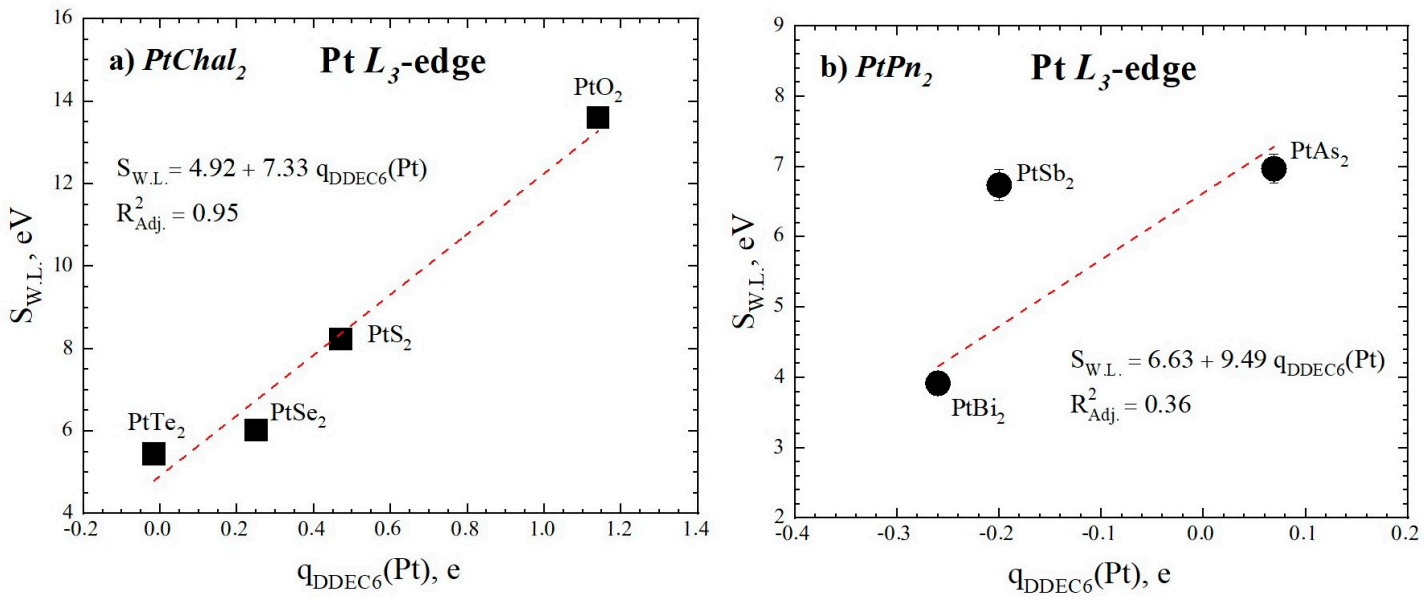

Figure 6. The correlation between the white line area $\left(\mathrm{S}_{\mathrm{W} . \mathrm{L} .}\right)$ of $\mathrm{Pt} L_{3}$-edge spectra and the Pt DDEC6 charge. (a) PtChal 2 and (b) $\mathrm{PtPn}_{2}$ groups
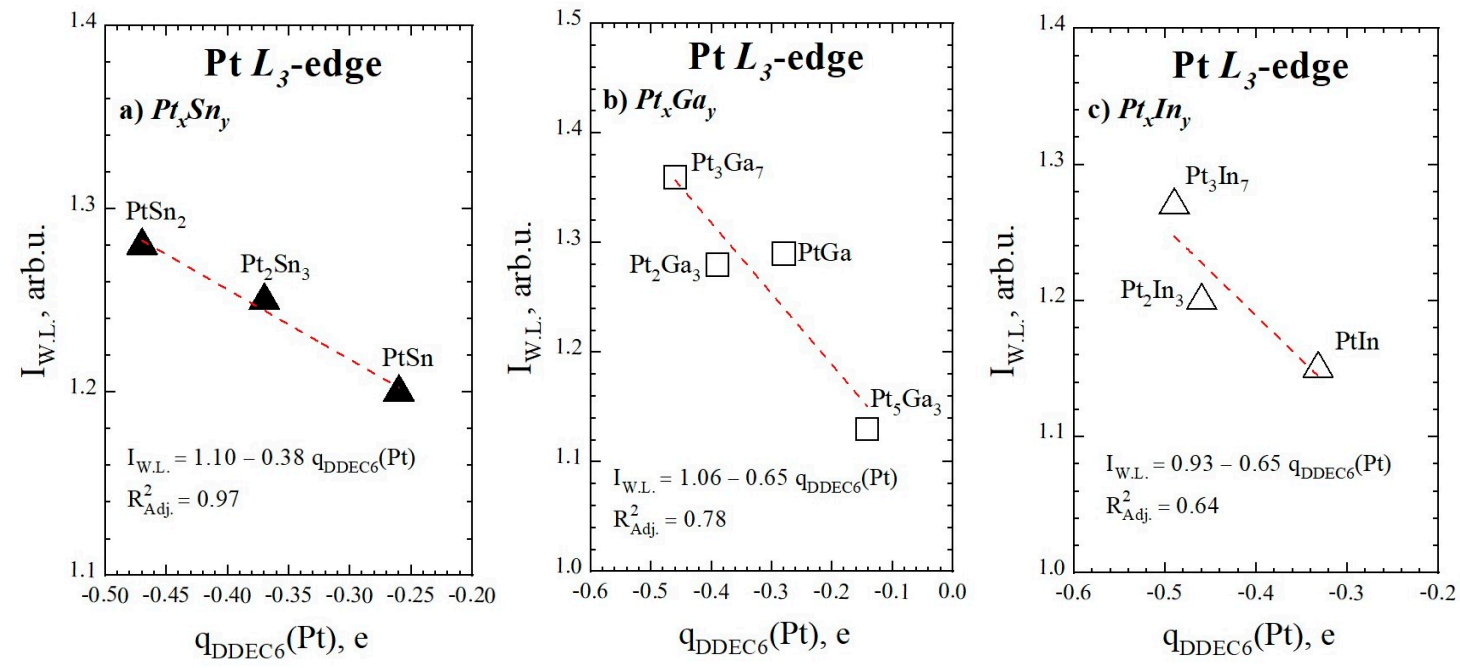

Figure 7. The correlation between the white line intensity ( $\left.\mathrm{I}_{\mathrm{W} . \mathrm{L} .}\right)$ of $\mathrm{Pt} L_{3}$-edge spectra and the Pt DDEC6 charge. (a) $P t_{x} S n_{y}$, (b) $P t_{x} G a_{y}$, and (c) $P t_{x} I n_{y}$ groups. 

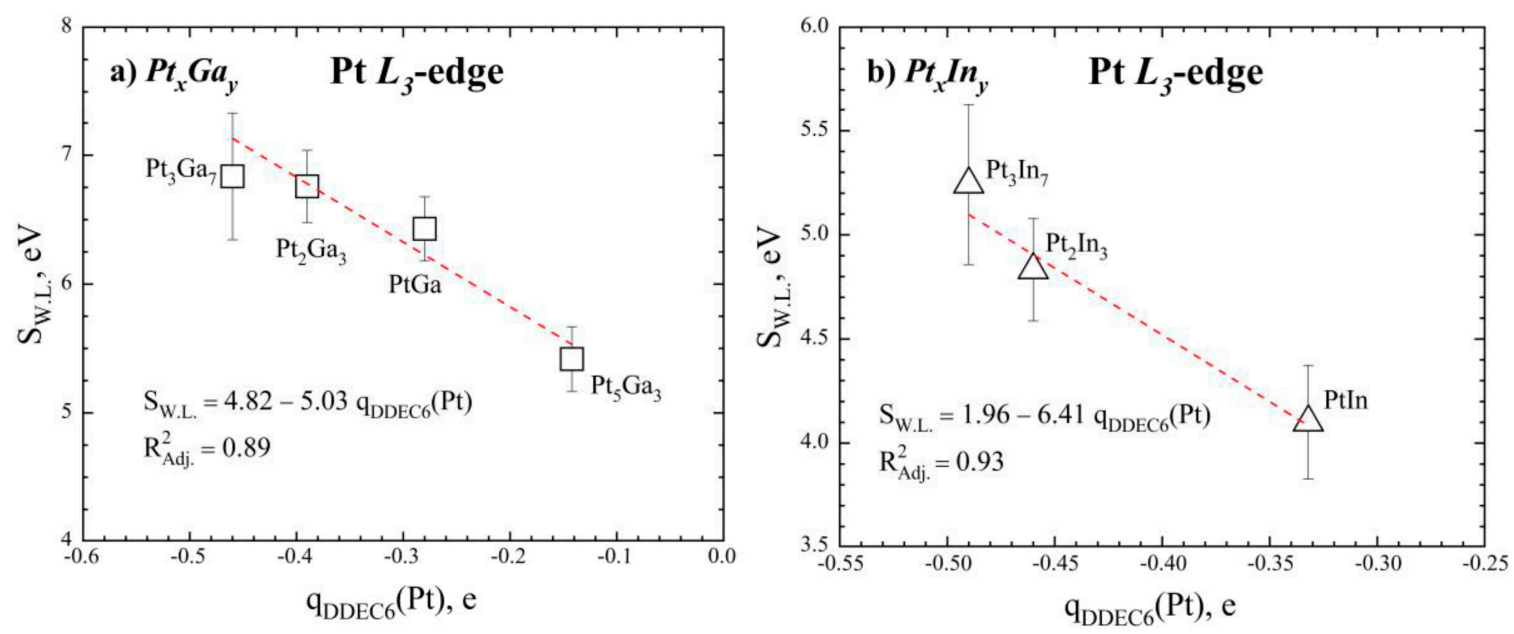

Figure 8. The correlation between the white line area $\left(\mathrm{S}_{\mathrm{W} . \mathrm{L} .}\right)$ of $\mathrm{Pt} L_{3}$-edge spectra and the Pt DDEC6 charge. (a) $P t_{x} G a_{y}$ and (b) $P t_{x} I n_{y}$ groups.

\section{Discussion}

\subsection{Partial Atomic Charges}

Figure 9a plots the trends of the partially atomic charges of Pt with respect to the electronegativity of ligands. All of the studied compounds followed the general trends of increasing partially charged $\mathrm{Pt}$ when ligand electronegativity increased. The trends are described by the following equations:

$$
\begin{gathered}
\mathrm{qDDEC}_{\mathrm{DD}}(\mathrm{Pt})=0.70 \times x-1.58 \\
\mathrm{qDDEC}_{\mathrm{DDt}}(\mathrm{Pt})=-5.41+3.47 \times x-0.46 \times \chi^{2}
\end{gathered}
$$

These equations can be used to predict the charge state of $\mathrm{Pt}$ in binary compounds using ligand electronegativity. The Pt partial charge in the $P t L_{2}$ group increased much more sharply when ligand electronegativity increased compared to the Pt partial charge in the PtL group. The difference in the slope of the trends is caused by a more effective charge transfer in or out of $\mathrm{Pt}$ with the increase of the number of ligands-electron donors $(\mathrm{q}(\mathrm{Pt})<0)$ or acceptors $(\mathrm{q}(\mathrm{Pt})>0)$ in $P t L_{2}$ group. Figure 9a illustrates that "formal" charges do not always adequately describe the charge state of a metal in a compound. For example, the "formal" oxidation state of $\mathrm{Pt}$ in $\mathrm{PtTe}_{2}$ (moncheite) and $\mathrm{PtAs}_{2}$ (sperrylite) is +4 , whereas in $\mathrm{PtS}$ (cooperite) the "formal" oxidation state of $\mathrm{Pt}$ is +2 . However, it follows from Figure 9a that the calculated partial atomic charge located on $\mathrm{Pt}$ in $\mathrm{Pt}^{2+} \mathrm{S}$ greatly exceeded the partial charge of $\mathrm{Pt}_{\mathrm{t}} \mathrm{Pt}^{4+} \mathrm{Te}_{2}$ and $\mathrm{Pt}^{4+} \mathrm{As}_{2}$. The reason for these discrepancies arises from the different degrees of ionicity in the crystals. The approach of the "formal" oxidation states works well for the ionic crystals and is incorrect for the covalent bonding.

Figure $9 \mathrm{~b}$ shows that the impact of the ligand-to- $\mathrm{Pt}$ ratio on the charge state of $\mathrm{Pt}$ depends on ligand electronegativity. For the mostly covalent bonding (the electronegativities of $\mathrm{Pt}$ and ligand close to each other), the slope weakly depends on the number of the ligands ( $\mathrm{PtTe}_{\mathrm{y}}$ case). The greater the difference in the electronegativity, the sharper the slope $\mathrm{q}(\mathrm{Pt})$ vs. $\mathrm{n}(\mathrm{L}) / \mathrm{n}(\mathrm{Pt})$, and the larger the absolute value of the Pt partial charge. For the ligands-electron acceptors $(\mathrm{L})(\chi(\mathrm{L})>\chi(\mathrm{Pt}))$, the overall valence electron density shifts out of $\mathrm{Pt}$ and the slope $\mathrm{q}(\mathrm{Pt})$ vs. $\mathrm{n}(\mathrm{L}) / \mathrm{n}(\mathrm{Pt})$ was positive $\left(P t S_{y}\right.$ case). When $\chi(\mathrm{L})<\chi(\mathrm{Pt})$, the slope is negative because the larger number of ligands-electron donors yield more valence electrons localized at the Pt site (the case of intermetallic compounds). 

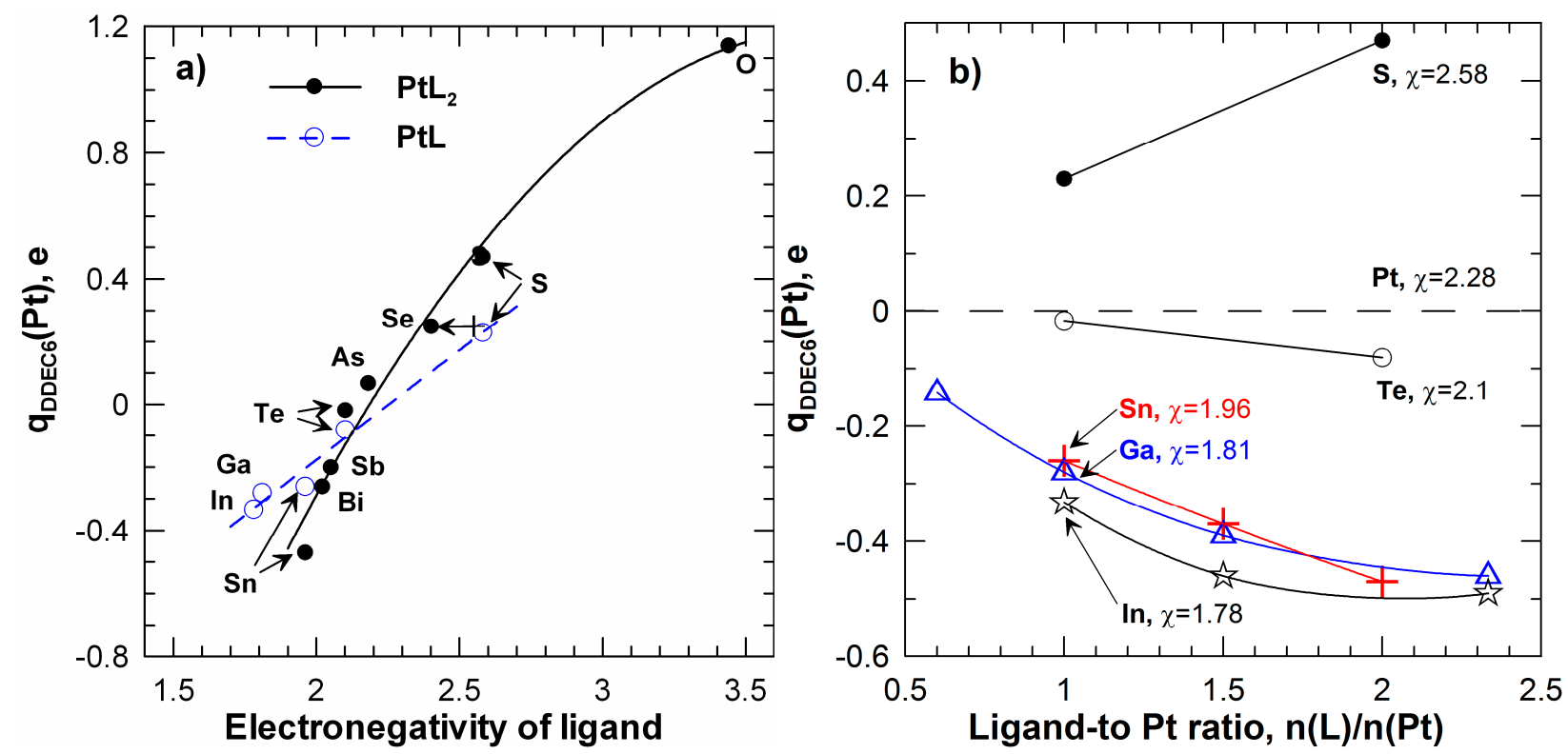

Figure 9. The partial atomic charges of Pt (DDEC6 method): a) calculated for $\mathrm{PtL}_{2}$ and $\mathrm{PtL}$ compounds as a function of electronegativity of the ligand, b) calculated for compounds with different ligand-to-Pt ratio $\left(\mathrm{PtS}_{\mathrm{y}}, \mathrm{PtTe}_{\mathrm{y}}, \mathrm{Pt}_{\mathrm{x}} \mathrm{Sn}_{\mathrm{y}}, \mathrm{Pt}_{\mathrm{x}} \mathrm{Ga}_{\mathrm{y}}\right.$, and $\left.P t_{x} I_{y}\right)$ as a function of the ratio. Symbols correspond to calculated values. In (a), the value of the electronegativity of Se was changed from 2.55 (cross, [3]) to 2.4 (closed circle, Pauling [35]). In (b), the ligand is indicated and the electronegativity of the ligand $\chi$ is given for each compound group.

\subsection{XANES Spectra Parameters}

After analyzing the partial atomic charges given in the previous section, the general trends of the Pt charge state as a function of a compound's chemical composition were revealed. The details of the distribution of the electron density can be retrieved from X-ray absorption spectroscopy results. In the present study, we recorded the spectra of $\operatorname{Pt} L_{1,2,3}$-edges. These absorption edges were mostly related to the following electronic transitions: $2 s \rightarrow 6 p$ ( $L_{1}$-edge) and $2 p \rightarrow 5 d$ ( $L_{2,3}$-edges) (Supplementary Materials $\left.\mathrm{D}\right)$. Accordingly, the parameters of the $L$--edge spectra (i.e., the white line intensity and area) were related to the density of Pt $5 d$ and hybridized 6sp states. Lytle et al. [6] found that the intensity and area of the white line at $L_{3}$ was proportional to the number of vacancies in the $d$ states. The authors compared the white line area at the $L_{3}$-edge for metallic $\mathrm{Au}, \mathrm{Pt}$, and $\mathrm{Ir}$, as well as their compounds. We found that the white line area increased when the difference in the electronegativity between the metal absorber atom and the ligand increased. Mansour et al. [7] suggested a method for quantitatively evaluating the number of vacant $d$ states on the basis of $L_{2,3}$ absorption edge spectra analysis. In this method, the total X-ray absorption coefficient is comprised of the contributions that arise due to the transition of unoccupied $d$ states and contributions that arise due to all other transitions. The second contribution is difficult to evaluate and, therefore, the method of Mansour et al. [7] determines that the changes in the white line areas (and the number of vacant $d$ states) is relative to the pure metal. The total number of holes (vacancies) in the $d$ orbitals was thus evaluated using the relative white line area at $L_{2}\left(d_{3 / 2}\right.$ orbitals) and the difference between the scaled areas at $L_{3}$ - and $L_{2}$-edges ( $d_{5 / 2}$ orbitals). The exact number of vacant $d$ states is of little interest for geological sciences (although, if necessary, it can be calculated using the spectra presented in Supplementary Materials B). Besides, geological samples often are diluted with respect to the studied element, and the record of good quality $L_{2}$-edge spectra is possible. Therefore, in the present study we did not attempt to provide a quantitative evaluation of the unoccupied density of $d$ states, but instead concentrated on the empirical correlations between the parameters of the $L_{1,2,3}$-edges spectra vs. the calculated partial atomic charges of $\mathrm{Pt}$ and ligand electronegativities. 
Figure 10 summarizes the data on the intensity of the $L_{1,2,3}$-edges for all the studied samples. In groups $\mathrm{PtChal}_{2}$ and $\mathrm{PtPn}_{2}$, the white line intensity at all the absorption edges increased when ligand electronegativity increased. This is a "normal" behavior of the spectral features as it implies an increase in the number of vacancies of the valence $5 d$ and $6 p$ orbitals of Pt when ligand electronegativity increases. The groups of intermetallic compounds $P t_{x} S n_{y}, P t_{x} G a_{y}$, and $P t_{x} I n_{y}$ exhibit apparently anomalous behavior: the white line intensity at the $L_{2,3}$-edges (the number of electronic vacancies (holes) in $d$ orbitals) increased when the number of ligands-electron donors increased. Similar behavior was observed in $\mathrm{Au}-\mathrm{Cu}$ alloys (cf. [8]). It was found that there was a loss of $d$ electrons at the $\mathrm{Au}$ site when $\mathrm{Cu}$ concentration increased despite higher Au electronegativity $(\chi(\mathrm{Au})=2.54 \mathrm{vs} . \chi(\mathrm{Cu})=1.90)$. By means of combining the data obtained using $X$-ray absorption spectroscopy, $X$-ray photoelectron spectroscopy, and Mössbauer spectroscopy, were determined that the decrease of the number of $d$ electrons at the Au site was overcompensated by a gain of $s-p$-like electron density. As a result, the total electron density at the $\mathrm{Au}$ site increased when $\mathrm{Cu}$ (electron-donor) concentration increased, which is in accord with the electronegativity rule. Kuhn and Sham [8] described the charge redistribution upon alloying in the Au-Cu system in the framework of the charge compensation model. They evaluated the loss of $5 d \mathrm{Au}$ electrons and the conjugated gain of combined $s-p$ (mostly $6 s$ ) ones. Our results showed that the charge compensation scheme can be applied to Pt-bearing compounds. As can be seen in Figure 10, in the groups of intermetallic compounds $P t_{x} S n_{y}$ and $P t_{x} G a_{y}$, the increase of the white line intensity at the $L_{2,3}$-edges (transitions to $5 d$ states) was accompanied by a decrease of the $L_{1}$-edge white line intensity (transitions to $6 p$ states). Therefore, like the $\mathrm{Au}-\mathrm{Cu}$ system, the increase of the total electron density at the Pt site can be supported by the conduction $6 s p$ electron density gain.

The white line parameters determined in the present study can be compared with the published values. Lytle et al. [6] determined the difference in the $\mathrm{Pt} L_{3}$-edge white line area between $\mathrm{PtO}_{2}$ and $\mathrm{Pt}$ as $\Delta A\left(\mathrm{PtO}_{2}\right)=8.4 \mathrm{eV}$. In the present study, the value of $\Delta A\left(\mathrm{PtO}_{2}\right)=8.8 \mathrm{eV}$ was obtained from the area of the Lorentzian function. The values were in exceptionally good agreement despite the use of different calculation methods. Lytle et al. [6] integrated the area under the normalized spectra in the vicinity of the white line, whereas in the present study the normalized spectra were deconvoluted to arctangent and Lorentzian functions, and the area of the Lorentzian function was assigned to the white line area. Our attempt to reproduce the calculations of Lytle et al. [6] and to calculate the difference between the total areas under the white lines of $\mathrm{PtO}_{2}$ and $\mathrm{Pt}$ (integration limits -10 to $+10 \mathrm{eV}$ from the absorption edge, Supplementary materials $\mathrm{C}$, Table $\mathrm{C} 5)$ yielded $\Delta A\left(\mathrm{PtO}_{2}\right)=3.7 \mathrm{eV}$. The disagreement can be explained by the differences in the normalization method, integration limits, and integration method. In view of good agreement between the area of Lorentzian function (this study) and $\Delta A\left(\mathrm{PtO}_{2}\right)$ value of Lytle et al. [6] and the simplicity of our method, the use of the Lorentzian to model the white line behavior was the best choice for the purposes of the present work. We again noted that we did not attempt to calculate the exact number of $d$-holes, but developed empirical correlations between the parameters of the partial Pt atomic charges and XANES spectral features.

Figure 11a,b shows the effect of the compound stoichiometry on the white line parameters. In the figure the $\mathrm{Pt} L_{3}$-edge, white line intensity (a) and area (b) were plotted as a function of the ligand-to-Pt ratio. In all the studied systems (Pt-S, Pt-Te, Pt-Ga, Pt-Sn, and $\mathrm{Pt}-\mathrm{In}$ ) an increase of the number of ligands per Pt atom caused the increase of the white line parameters that corresponded to the loss of the $5 d$ electrons. The "anomalous" positive trends in Figure 11a,b for the ligands and electron-donors $(\chi(\mathrm{L})<\chi(\mathrm{Pt}))$ were not in line with the "normal" negative trends for the Pt partial atomic charge observed for the same compounds in Figure 11b. As we noted above in the discussion of Figure 10, this inconsistency can be explained by the charge compensation model. According to the model, a decrease of the number of $d$ electrons was overcompensated by the gain of the $s-p$ electrons. As a result, the total electron density at the Pt site grew with the increase of the number of ligands-electron donors (Te, Ga, Sn, In), as required by electronegativity arguments. 


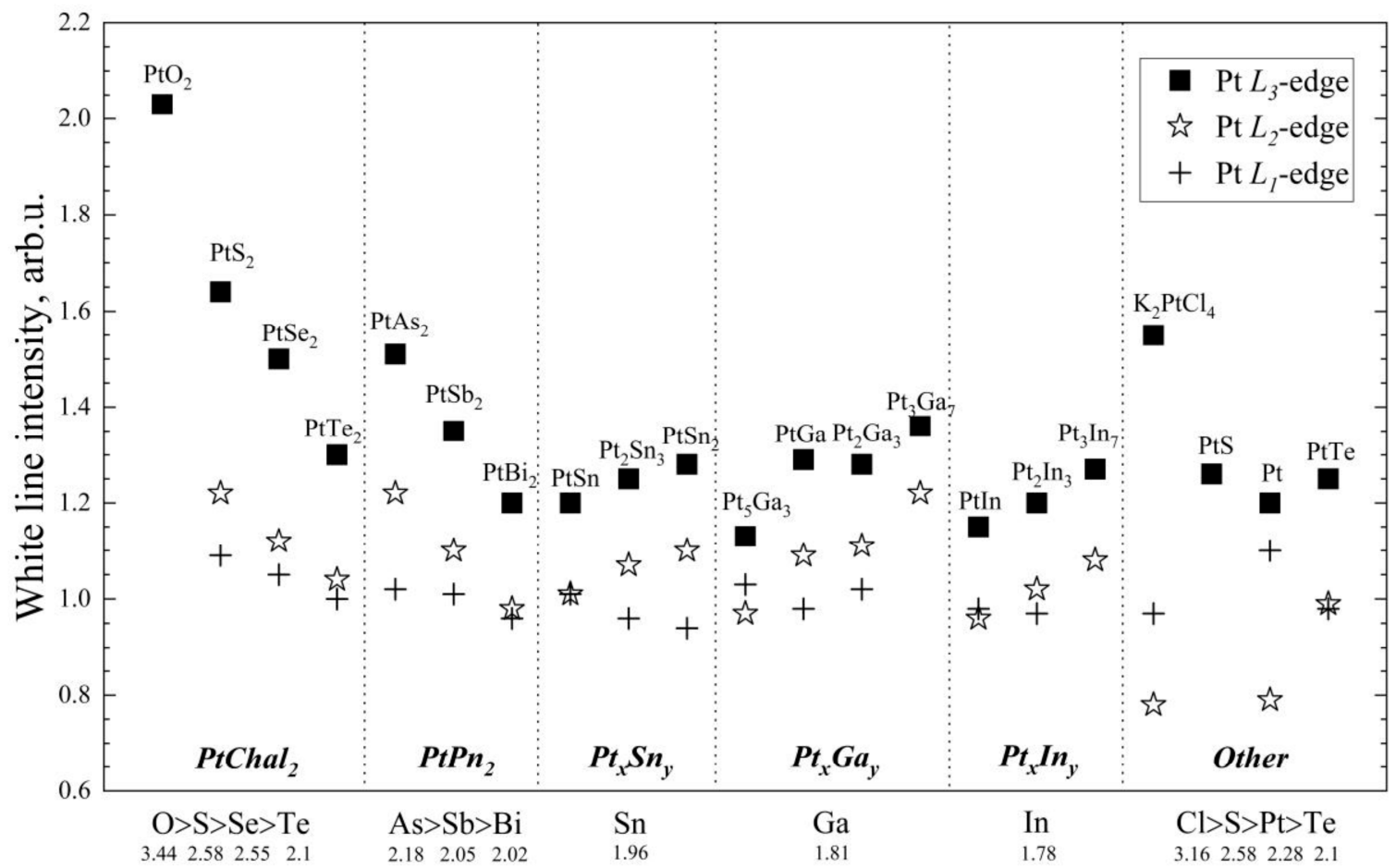

Figure 10. Plot showing normalized intensity of white line at the $\mathrm{Pt} L_{1,2,3}$-edges. The ligand electronegativities are indicated in the $\mathrm{X}$ axis.
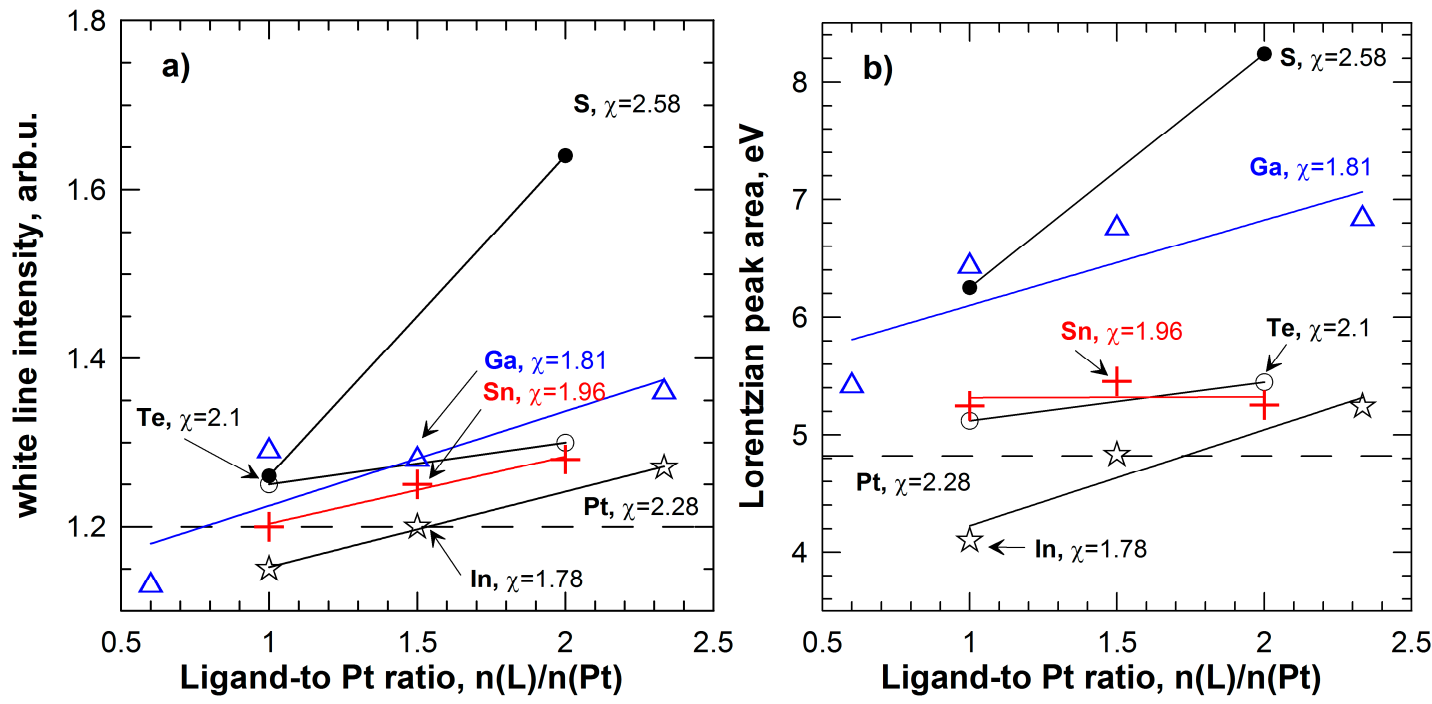

Figure 11. Normalized intensity of $\mathrm{Pt} L_{3}$-edge white line (a), and area of Lorentzian function which approximate the white line (b). The ligand-to Pt ratio is shown in X axis. Symbols correspond to calculated values. The ligand type and the electronegativity of the ligand $\chi$ is given for each group of compounds.

\subsection{The Charge State of Pt in Pyrite}

The results obtained for the $\mathrm{PtChal}_{2}$ group-i.e., the correlations between intensity and white line area, as well as the Pt DDEC6 charge-were used to predict the Pt charge in synthetic Pt-bearing pyrite crystals. Filimonova et al. [36] found that Pt can substitute for $\mathrm{Fe}$ in the structure of pyrite with the formation $\left(\mathrm{Fe}_{1-\mathrm{x}} \mathrm{Pt}_{\mathrm{x}}\right) \mathrm{S}_{2}$ solid solution. In the present study, the $\mathrm{Pt} L_{3}$-edge white line parameters were determined from the spectrum of 
Pt-bearing pyrite $(0.24 \mathrm{wt} . \% \mathrm{Pt})$, adopted from [36]. The partial atomic charge of $\mathrm{Pt}$ in this sample equaled $+0.42 \mathrm{e}(+0.44 \mathrm{e})$ according to our correlation model (Figure 12).
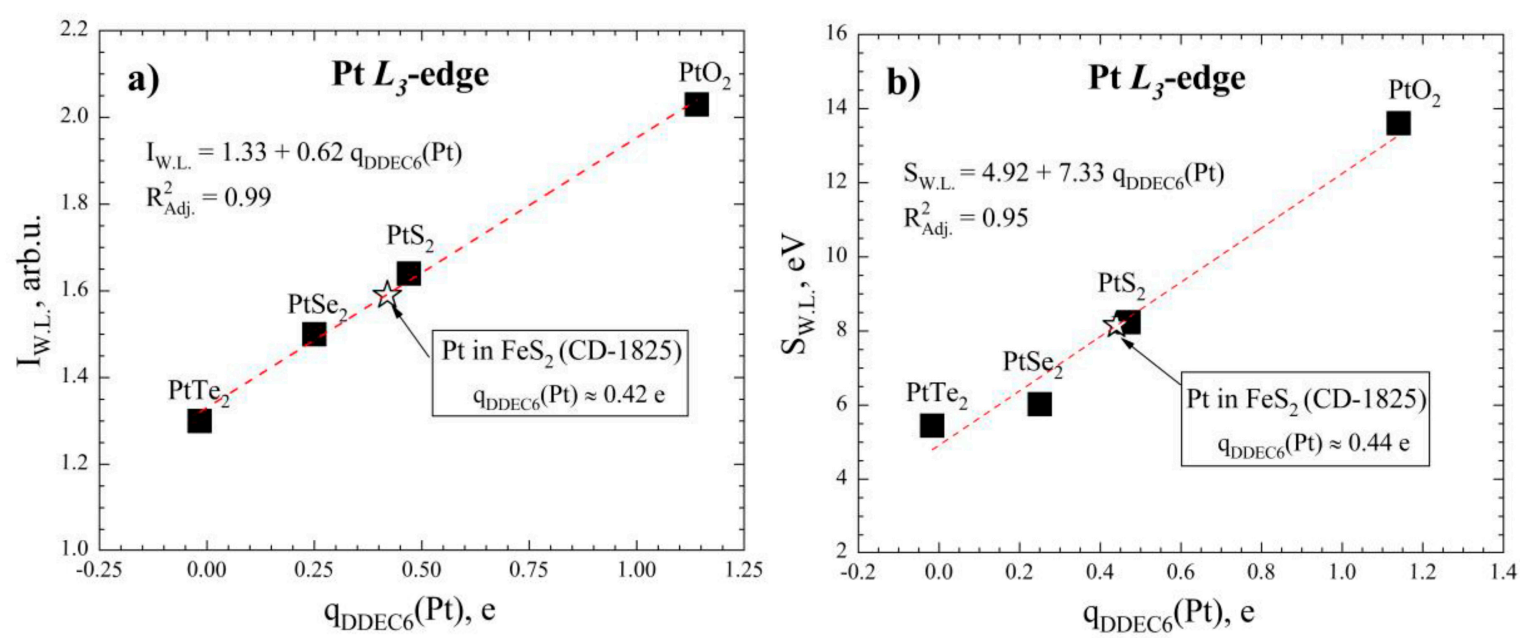

Figure 12. Plot showing the estimated DDEC6 charge of Pt in pyrite (star) using the experimental linear correlation between the white line intensity $(\mathbf{a})$, area $(\mathbf{b})$ and the DDEC6 charge of Pt.

To verify the experimental data, the atomic geometry optimization of Pt-bearing pyrite was performed using the DFT method. The Pt DDEC6 charges were calculated for the relaxed structure. The calculation results are given in Table 4. A good agreement was observed between parameters of the calculated geometry of Pt-bearing pyrite and results of the EXAFS analysis [36]. The difference between the DFT and EXAFS-based interatomic distances of the nearest three shells of Pt was less than $2 \%$. The Pt DDEC6 charge in the simulated pyrite structure was $+0.43 \mathrm{e}$, and was in excellent agreement with the experimental results. Note that the positive charge of the nearest to Pt atoms of $\mathrm{Fe}$, which were located in the 2nd coordination shell, was close to the Fe charge in pure $\mathrm{FeS}_{2}$. The calculations of the white line area and the Pt partial charge performed with MATHCAD program are given in Supplementary materials C, Tables C4-C6. In this case, the best agreement with the DFT calculations was observed for the integration limits from -10 to $+10 \mathrm{eV}\left(\mathrm{q}_{\mathrm{DDEC} 6}(\mathrm{Pt})=+0.38 \mathrm{e}\right)$ and -10 to $+13 \mathrm{eV}\left(\mathrm{q}_{\mathrm{DDEC} 6}(\mathrm{Pt})=+0.48 \mathrm{e}\right)$, relative to the edge energy determined as the inflection point of the arctangent function. We would like to note, however, that the results of this integration method are sensitive to integration limits.

The results obtained for the Pt-bearing pyrite justified the correlations developed in the present study. These results also confirmed the data provided by Filimonova et al. [36], who found that the state of "invisible" Pt in pyrite can be different from $\mathrm{PtS}_{2}$. According to DFT calculation results (Table 4) and the correlations based on the Pt partial charge in chalcogenides (Figure 12), the Pt partial charge in $\mathrm{PtS}_{2}(+0.47 \mathrm{e})$ is different from the $\mathrm{Pt}$ partial charge in the pyrite solid solution $(+0.43 \mathrm{e})$. This small but noticeable difference means that the local atomic environments of $\mathrm{Pt}$ in $\mathrm{PtS}_{2}$ and pyrite are inequivalent. 
Table 4. Results of determination of the charge state of atoms in pure and Pt-bearing pyrite.

\begin{tabular}{|c|c|c|c|c|c|c|}
\hline \multirow[b]{2}{*}{ Source } & \multicolumn{2}{|c|}{ Supercell Parameters } & \multicolumn{3}{|c|}{ Bond Length (R), Å } & \multirow[b]{2}{*}{ DDEC6 Charge } \\
\hline & a, $\AA$ & $\alpha^{\circ}$ & $\begin{array}{c}M-S(N=6) \\
M=F e, P t\end{array}$ & $\begin{array}{c}\mathrm{M}-\mathrm{S} \\
(\mathrm{N}=8)\end{array}$ & $\begin{array}{c}\text { M-Fe } \\
(N=12)\end{array}$ & \\
\hline \multicolumn{7}{|c|}{$\mathrm{FeS}_{2}$} \\
\hline $\begin{array}{l}\text { PDF-4+ 2018, } \\
\# 00-042-1340\end{array}$ & 10.8358 & 90 & 2.2644 & $\begin{array}{c}3.4463 \text { and } 3.6132 \\
(\mathrm{~N}=6 \text { and } 2)\end{array}$ & 3.8310 & - \\
\hline DFT & 10.8126 & 90 & 2.2532 & $\begin{array}{c}3.463 \text { and } 3.575 \\
(\mathrm{~N}=6 \text { and } 2)\end{array}$ & 3.823 & $\begin{array}{l}+0.16(\mathrm{Fe}) \\
-0.08(\mathrm{~S})\end{array}$ \\
\hline \multicolumn{7}{|c|}{ Pt-bearing $\mathrm{FeS}_{2}$} \\
\hline DFT & 10.8283 & 90 & 2.387 & $\begin{array}{c}3.501 \text { and } 3.571 \\
(\mathrm{~N}=6 \text { and } 2) \\
\text { aver. }^{1}-3.519\end{array}$ & $\begin{array}{c}3.830 \text { and } 3.842 \\
(\mathrm{~N}=6 \text { and } 6), \\
\text { aver. }^{1}-3.836\end{array}$ & $\begin{array}{l}+0.43(\mathrm{Pt}) \\
+0.18(\mathrm{Fe}) \\
-0.11(\mathrm{~S})\end{array}$ \\
\hline EXAFS data ${ }^{2}$ & - & - & $2.35 \pm 0.01$ & $3.47 \pm 0.08$ & $3.81 \pm 0.02$ & $\begin{array}{l}+0.42\left(\mathrm{Pt}, \mathrm{I}_{\mathrm{W} . \mathrm{L}}\right) \\
+0.44\left(\mathrm{Pt}, \mathrm{S}_{\mathrm{W} . \mathrm{L}}\right)\end{array}$ \\
\hline
\end{tabular}

${ }^{1}$ aver. = average value (averaged over two coordination spheres). ${ }^{2}$ EXAFS data from [36]. Atomic charges determined from the correlations of white line parameter vs. charge (Figure 12a,b).

\section{Conclusions}

The charge state of $\mathrm{Pt}$ in compounds with chalcogens $(\mathrm{O}, \mathrm{S}, \mathrm{Se}, \mathrm{Te})$, pnictogens $(\mathrm{As}$, $\mathrm{Sb}, \mathrm{Bi}$ ), and in intermetallic compounds with $\mathrm{Sn}, \mathrm{Ga}$, and In was studied via quantumchemical calculations (QTAIM and DDEC6 methods) and XANES spectra analysis. The quantum chemical calculations were used to reveal the general trends between the partial atomic charge of $\mathrm{Pt}$ vs. ligand electronegativity. The analysis of the XANES spectral features enabled to determine the effect of the ligand type and the compound stoichiometry on the charge transfer between electronic shells. The Pt partial charge increased when ligand electronegativity increased, but the slope of the correlation lines depended on the phase stoichiometry. The Pt partial charge increased sharply when ligand electronegativity for $\mathrm{PtL}_{2}$ compounds grew, compared to PtL. The XANES spectroscopy demonstrated that the number of $5 d$ ( $L_{2,3}$ absorption edges) and $6 p$ ( $L_{1}$-edge) electrons at the Pt site decreased when ligand electronegativity increased in the groups of chalcogenides and pnictides, which was consistent with the electronegativity arguments. However, the changes of the white line parameters at $\mathrm{Pt} \mathrm{L}_{3}$-edge as a function of a substance stoichiometry followed the trend opposite to the electronegativity rule. In all of the studied compounds, the number of ligands increased per Pt atom, which was a result of increased white line intensity and area. These changes indicate the increase of the number of $d$-shell vacancies with the increase of the number of ligands, including the ligands-electron donors (Te, $\mathrm{Sn}, \mathrm{Ga}, \mathrm{In})$, for which the opposite trend is expected. These findings can be explained by the charge compensation model (e.g., Watson et al. [37], Kuhn and Sham [8]). The loss of the Pt $d$ electrons in compounds with low ligand electronegativity $(\chi(\mathrm{Pt})>(\chi(\mathrm{L})$ is overcompensated by the gain of the hybridized $s-p$ electron density, which was traced by changes in the $L_{1}$-edge spectra parameters. As a result, the overall electron density at the $\mathrm{Pt}$ site followed the electronegativity rule. The correlation between the Pt partial charge in chalcogenides and the XANES parameters were used to determine the charge state of $\mathrm{Pt}$ in pyrite. The established correlations between the parameters of the spectral features and the Pt partial atomic charge can provide a simple tool to determine the states (electronic state and geometry at atomic level) of Pt in natural minerals of different composition.

Supplementary Materials: The following are available online at https:/ /www.mdpi.com/2075-163 X/11/1/79/s1, Supplementary Materials A: Parameters of the $\mathrm{Pt} \mathrm{L}_{1,2,3}$-edges spectra: energy range recorded during the experiment, parameters of background correction and normalization of the spectra (Supplementary materials A1); details of DFT calculations (Supplementary materials A2); initial crystallographic data and results of DFT calculations of the Pt partial atomic charges (Supplementary 
materials A3); the Pt $\mathrm{L}_{1}$-edge XANES spectra, results of the spectra analysis, and correlations between parameters of the spectral features and partial atomic charges (Supplementary materials A4); the $\mathrm{Pt} \mathrm{L}_{2}$ XANES spectra, results of the spectra analysis, and correlations between parameters of the spectral features and partial atomic charges (Supplementary materials A5); correlations between the parameters of the Pt $\mathrm{L}_{3}$ spectral features and DDEC6 and Bader charges of Pt (Supplementary materials A1-A14). Supplementary Materials B: The Pt $\mathrm{L}_{1,2,3}$-edges spectra in the format of Athena projects. Supplementary Materials C: Results of XANES Pt L $\mathrm{L}_{3}$ spectra deconvolution (Supplementary materials $\mathrm{C} 1$ ); parameters used for the white line area calculation using MATHCAD program and the calculation results (Supplementary materials C1-C6). Supplementary Materials D: Results of FDMNES calculations of the $\mathrm{Pt} \mathrm{L}_{1,2,3}$-edges spectra of $\mathrm{PtS}_{2}$.

Author Contributions: P.V.E. performed the experiments and quantum chemical calculations, carried out the data treatment, and wrote the paper; A.L.T. organized the experimental work at Kurchatov Synchrotron and DFT calculations; D.A.C. carried out the synthesis experiments; M.S.N. performed the XRD analysis and treatment of crystal chemical data; B.R.T. designed the study, participated in the analysis of the experimental and computational results, and wrote the paper; all authors participated in the manuscript preparation. All authors have read and agreed to the published version of the manuscript.

Funding: This study was supported by RFBR grant No. 20-35-70049, the program 211 of the Russian Federation Government, agreement No. 02.A03.21.0006, by the Russian Government Program of Competitive Growth of Kazan Federal University, and by Ministry of Education and Science of the Russian Federation grant No. 075-15-2020-802.

Acknowledgments: We are grateful to Aleksey Nekrasov (IEM RAS) for EPMA analysis of Pt compounds, Nikolay Trofimov (IGEM RAS) for useful comments on processing the experimental spectra, and Olga Filimonova (IGEM RAS) for provision of the experimental spectra of Pt-bearing pyrite. Quantum chemical calculations were carried out using computing resources of the federal collective usage center Complex for Simulation and Data Processing for Mega-science Facilities at NRC "Kurchatov Institute", http:/ / ckp.nrcki.ru/.

Conflicts of Interest: The authors declare no conflict of interest.

\section{References}

1. Distler, V.V.; Sluzhenikin, S.F.; Cabri, L.J.; Krivolutskaya, N.A.; Turovtsev, D.M.; Golovanova, T.A.; Mokhov, A.V.; Knauf, V.V.; Oleshkevich, O.I. Platinum ores of the Noril'sk layered intrusions: Magmatic and fluid concentration of noble metals. Geol. Ore Depos. 2019, 41, 214-237.

2. Cabri, L.J. The platinum-group minerals. In The Geology, Geochemistry, Mineralogy and Mineral Benefication of Platinum-Group Elements; Cabri, L.J., Ed.; The Canadian Mineralogist: Ottawa, ON, Canada, 2002; pp. 13-129.

3. Cotton, F.A.; Wilkinson, G. Advanced Inorganic Chemistry, 3rd ed.; Interscience: New York, NY, USA, $1972 ;$ p. 1396.

4. Nishimura, S.; Dao, A.T.N.; Mott, D.; Ebitani, K.; Maenosono, S. X-ray absorption near-edge structure and x-ray photoelectron spectroscopy studies of interfacial charge transfer in gold-silver-gold double-shell nanoparticles. J. Phys. Chem. C 2012, 116, 4511-4516. [CrossRef]

5. Mott, N.F. The basis of the electron theory of metals, with special reference to the transition metals. Proc. Phys. Soc. A 1949, 62, 416-422. [CrossRef]

6. Lytle, F.W.; Wei, P.S.P.; Greegor, R.B.; Via, G.H.; Sinfeit, J.H. Effect of chemical environment on magnitude of X-ray absorption resonance at $\mathrm{L}_{\mathrm{III}}$ edges. studies on metallic elements, compounds, and catalysts. J. Chem. Phys. 1979, 70, 4849-4855. [CrossRef]

7. Mansour, A.N.; Cook, J.W., Jr.; Sayers, D.E. Quantitative technique for the determination of the number of unoccupied d-electron states in a platinum catalyst using the $\mathrm{L}_{2,3} \mathrm{X}$-ray absorption edge spectra. J. Phys. Chem. 1984, 88, 2330-2334. [CrossRef]

8. Kuhn, M.; Sham, T.K. Charge redistribution and electronic behavior in a series of Au-Cu alloys. Phys. Rev. B 1994, 49, 1647-1661. [CrossRef] [PubMed]

9. Bzowski, A.; Yiu, Y.M.; Sham, T.K. Charge redistribution in Au-metalloid intermetallics: A Au L2,3-edge x-ray-absorption study. Phys. Rev. B 1995, 51, 9515-9520. [CrossRef] [PubMed]

10. Bader, R.F.W.; MacDougall, P.J.; Lau, C.D.H. Bonded and nonbonded charge concentrations and their relation to molecular geometry and reactivity. J. Am. Chem. Soc. 1984, 106, 1594-1605. [CrossRef]

11. Bader, R.F.W.; Matta, C.F. Atomic charges are measurable quantum expectation values: A rebuttal of criticisms of QTAIM charges. J. Phys. Chem. A 2004, 108, 8385-8394. [CrossRef]

12. Reed, A.E.; Curtiss, L.A.; Weinhold, F. Intermolecular interactions from a natural bond orbital, donor-acceptor viewpoint. Chem. Rev. 1988, 88, 899-926. [CrossRef] 
13. Manz, T.A.; Sholl, D.S. Chemically meaningful atomic charges that reproduce the electrostatic potential in periodic and nonperiodic materials. J. Chem. Theory Comput. 2010, 6, 2455-2468. [CrossRef] [PubMed]

14. Manz, T.A.; Sholl, D.S. Improved atoms-in-molecule charge partitioning functional for simultaneously reproducing the electrostatic potential and chemical states in periodic and non-periodic materials. J. Chem. Theory Comput. 2012, 8, 2844-2867. [CrossRef] [PubMed]

15. Li, L.; Morrill, M.R.; Shou, H.; Barton, D.G.; Ferrari, D.; Davis, R.J.; Agrawal, P.K.; Jones, C.W.; Sholl, D.S. On the relationship between Mo K-edge energies and DFT computed partial charges. J. Phys. Chem. C 2013, 117, 2769-2773. [CrossRef]

16. Kaur, R.; Kumar, A.; Czyzycki, M.; Migliori, A.; Karydas, A.G.; Puri, S. A study of the influence of chemical environment on the $\mathrm{L}_{\mathrm{i}}(\mathrm{i}=1-3)$ subshell $\mathrm{X}$-ray intensity ratios and the $\mathrm{L}_{3}$ absorption-edge energy for some compounds of ${ }_{66}$ Dy using synchrotron radiation. X-ray Spectrom. 2019, 1-12. [CrossRef]

17. Fogarty, R.M.; Rowe, R.; Matthews, R.P.; Clough, M.T.; Ashworth, C.R.; Brandt, A.; Corbett, P.J.; Palgrave, R.G.; Smith, E.F.; Bourne, R.A.; et al. Atomic charges of sulfur in ionic liquids: Experiments and calculations. Faraday Discuss. 2018, 206, 183-201. [CrossRef]

18. Fogarty, R.M.; Matthews, R.P.; Ashworth, C.R.; Brandt-Talbot, A.; Palgrave, R.G.; Bourne, R.A.; Vander Hoogerstraete, T.; Hunt, P.A.; Lovelock, K.R.J. Experimental validation of calculated atomic charges in ionic liquids. J. Chem. Phys. 2018, 148, 193817. [CrossRef] [PubMed]

19. Kullerud, G. Experimental techniques in dry sulfide research. In Research Techniques for High Pressure and High Temperature; Ulmer, G.C., Ed.; Springer-Verlag: New York, NY, USA, 1971; pp. 288-315.

20. Lyakishev, N.P. Phase Diagrams of Binary Metallic Systems: Handbook; Mashinostroenie: Moscow, Russian, 1996; Volume 1, p. 992.

21. Lyakishev, N.P. Phase Diagrams of Binary Metallic Systems: Handbook; Mashinostroenie: Moscow, Russian, 1997 ; Volume 2, p. 1024.

22. Lyakishev, N.P. Phase Diagrams of Binary Metallic Systems: Handbook; Mashinostroenie: Moscow, Russian, 2000 ; Volume 3, p. 448.

23. Chernyshov, A.A.; Vegizhanin, A.A.; Zubavichus, Y.V. Structural materials science end-station at the Kurchatov synchrotron radiation source: Recent instrumentation upgrades and experimental results. Nucl. Instrum. Methods Phys. Res. A 2009, 603, 95-98. [CrossRef]

24. Ravel, B.; Newville, M. On ATHENA, ARTEMIS, HEPHAESTUS: Data analysis for X-ray absorption spectroscopy using IFEFFIT. J. Synchrotron Rad. 2005, 12, 537-541. [CrossRef]

25. Giannozzi, P.; Baroni, S.; Bonini, N.; Calandra, M.; Car, R.; Cavazzoni, C.; Caresoli, D.; Chiarotti, G.L.; Cococcioni, M.; Dabo, I.; et al. QUANTUM ESPRESSO: A modular and open-source software project for quantum simulations of materials. J. Phys. Condens. Matter 2009, 21, 395502. [CrossRef]

26. Blöhl, P.E. Projector augmented-wave method. Phys. Rev. B 1994, 50, 17953-17979. [CrossRef]

27. Kresse, G.; Joubert, D. From ultrasoft pseudopotentials to the projector augmented-wave method. Phys. Rev. B 1999, 59, 1758-1775. [CrossRef]

28. Perdew, J.P.; Burke, K.; Ernzerhof, M. Generalized gradient approximation made simple. Phys. Rev. Lett. 1996, 77, 3865-3868. [CrossRef] [PubMed]

29. Vydrov, O.A.; Van Voorhis, T. Nonlocal van der Waals density functional: The simpler the better. J. Chem. Phys. 2010, 133, 244103. [CrossRef] [PubMed]

30. Otero-de-la-Roza, A.; Blanco, M.A.; Martín Pendás, A.; Luaña, V. Critic: A new program for the topological analysis of solid-state electron densities. Comput. Phys. Comm. 2009, 180, 157-166. [CrossRef]

31. Otero-de-la-Roza, A.; Johnson, E.R.; Martín Pendás, A.; Luaña, V. Critic2: A program for real-space analysis of quantum chemical interactions in solids. Comput. Phys. Comm. 2014, 185, 1007-1018. [CrossRef]

32. SOURCEFORGE (Program Computing DDEC Atomic Charges). Available online: http://ddec.sourceforge.net (accessed on 25 February 2020).

33. Manz, T.A.; Limas, N.G. Introducing DDEC6 atomic population analysis: Part 1. charge partitioning theory and methodology. RSC Adv. 2016, 6, 47771-47801. [CrossRef]

34. Limas, N.G.; Manz, T.A. Introducing DDEC6 atomic population analysis: Part 2. computed results for a wide range of periodic and nonperiodic materials. RSC Adv. 2016, 6, 45727-45747. [CrossRef]

35. Pauling, L. The Nature of the Chemical Bond and the Structure of Molecules and Crystals: An Introduction to Modern Structural Chemistry, 3rd ed.; Cornell University Press: New York, NY, USA, 1960; p. 644.

36. Filimonova, O.N.; Nickolsky, M.S.; Trigub, A.L.; Chareev, D.A.; Kvashnina, K.O.; Kovalchuk, E.V.; Vikentyev, I.V.; Tagirov, B.R. The state of platinum in pyrite studied by X-ray absorption spectroscopy of synthetic crystals. Econ. Geol. 2019, 114, 1649-1663. [CrossRef]

37. Watson, R.E.; Hudis, J.; Perlman, M.L. Charge flow and d compensation in gold alloys. Phys. Rev. B 1971, 4, 4139-4144. [CrossRef] 